\title{
The 10-Point Plan 2021: Updated Concepts for Improved Procedural Safety During Facial Filler Treatments
}

\author{
Izolda Heydenrych $\mathbb{D}^{\prime}$ \\ Koenraad De Boulle $\mathbb{D}^{2}$ \\ Krishan Mohan Kapoor (iD ${ }^{3}$ \\ Dario Bertossi $\mathbb{D}^{4}$
}

'Cape Town Cosmetic Dermatology Centre, Century City, Cape Town, South Africa; ${ }^{2}$ Aalst Dermatology Clinic, Aalst, Belgium; ${ }^{3}$ Department of Plastic Surgery, Fortis Hospital, Mohali, India;

${ }^{4}$ Maxillofacial Department, University of Verona, Verona, Italy
Correspondence: Izolda Heydenrych Cape Town Cosmetic Dermatology Centre, Central Park on Esplanade, Postnet Suite 136, Century City, Cape Town, 7442, South Africa

Tel +27215527220

Fax +27 21 5527229

Email izoldaheydenrych@gmail.com

\begin{abstract}
Dermal filler treatments require constant reassessment for improving and safeguarding the rapidly evolving aesthetic field. Suboptimal injection technique, patient selection and product knowledge have touted a concerning increase in filler complications, with new challenges such as the COVID-19 pandemic leading to new paradigms in the understanding, prevention, diagnosis and treatment of complications. The updated 10-point plan has been developed to curtail complications through consideration of causative factors, categorized as patient, product, and procedure-related. Patient-related factors include a preprocedural consultation with careful elucidation of skin conditions (acne, rosacea, dermatitis), systemic disease (allergies, autoimmune disease, underlying bacterial and viral disease (herpes simplex virus, COVID-19 infection), medications (antineoplastic drugs, recreational drugs) and previous cosmetic procedures (including fillers and energy-based devices). Patient assessment should include standardized photography and also evaluate the role of social media, ethnicity, gender, generational, and LGBTQ+ needs. Specified informed consent for both adverse events and their treatment is essential due to the increase in vascular complications, including the risk of blindness. Product-related factors include the powerful advantage of reversibility when using hyaluronic acid (HA) products. Product characteristics such as molecular weight and filler degradation should be understood. Product layering over late or minimally degradable fillers is still inadvisable due to the initial filler being teased into reactivity. Procedural factors such as consistent photographic documentation, procedural planning, aseptic non-touch technique (ANTT), knowledge of topographical anatomy and angiosomes, and technical dexterity including pinch anatomy and needle skills are of pivotal importance. The final section is dedicated to algorithms and checklists for managing and treating complications such as allergic hypersensitivity reactions, vascular events, infection, edema and late-onset adverse events (LOAEs). The updated 10-point plan is a methodical strategy aimed at further minimising the risk of dermal filler complications.
\end{abstract}

Keywords: assessment, complications, dermal fillers, prevention, treatment

\section{Introduction}

The exponential increase in the use of injectable fillers has heralded unique safety requirements, mandating ongoing reappraisal of both procedural method and complication management.

As with the initial 10-point plan for avoiding hyaluronic acid dermal fillerrelated complications during facial aesthetic procedures and algorithms for management, ${ }^{1}$ this updated plan aims to establish a simple, user-friendly checklist for optimising patient factors, practical product knowledge and safer technique. 
Updated treatment and safety algorithms have been added in a visual format (Table 1, Figure 21, 22, 23).

\section{Patient-Related Factors} History and Selection

Frequently queried selection criteria include the following:
The Neoplastic Process and Antineoplastic Drugs

Filler safety is frequently queried in patients with cancer or on antineoplastics, cytotoxics, biologicals, or immunotherapy (Table 2). Conversely, the influence of fillers on the incidence, behavior, or aggravation of malignant tumors has been questioned, with the rapidly evolving field of onco-immunology raising awareness around

Table I A 10-Point Plan for Avoiding Filler Complications

\begin{tabular}{|c|c|c|c|}
\hline I. Patient & II. Product & III. Procedure & IV. Algorithms \\
\hline $\begin{array}{l}\text { I. History } \\
\text { - Skin } \\
\text { - Systemic disease } \\
\text { - Medication } \\
\text { - Procedures } \\
\text { Selection } \\
\text { - Skin, systemic disease } \\
\text { - Pretreat eg, acne, dermatitis } \\
\text { - Dental, vaccinations } \\
\text { - Routine procedures } \\
\text { - Cancer Rx } \\
\text { - Previous LOAE } \\
\text { - Body dysmorphic disorder }\end{array}$ & $\begin{array}{l}\text { 4. } \text { Reversibility } \\
\text { - Hyaluronidase } \\
\text { - } \text { Dilution, dosage types } \\
\text { - "Off-label"? }\end{array}$ & $\begin{array}{l}\text { 7. Photographs } \\
\text { - Pre and post } \\
\text { - SLR camera; consistent background } \\
\text { - No makeup or jewelry } \\
\text { - Rest and animation } \\
\text { - Angles and lighting } \\
\text { - Lateral: Frankfort plane } \\
\text { - Oblique: all } 4 \text { canthi }\end{array}$ & $\begin{array}{l}\text { Allergy/hypersensitivity } \\
\text { - Early: vitals, adrenalin, IV } \\
\text { - HI H2 antagonists } \\
\text { - Oral corticosteroids } \\
\text { - Propanol, ibuprofen } \\
\text { Edema/swelling } \\
\text { Time of onset }\end{array}$ \\
\hline $\begin{array}{l}\text { 2. Assessment } \\
\text { - Beauty, aging } \\
\text { - Ethnic nuancing } \\
\text { - Gender: } \\
\text { LGBTQ+ identifiers } \\
\text { - Wants vs needs } \\
\text { - Muscle dynamics and indirect } \\
\text { effects }\end{array}$ & $\begin{array}{l}\text { 5. Product } \\
\text { characteristics } \\
\text { - HA concentration } \\
\text { - Cross-linking }\end{array}$ & $\begin{array}{l}\text { 8. Procedural planning and aseptic } \\
\text { technique } \\
\text { - Technical flow } \\
\text { - Everything at hand } \\
\text { - ANTT } \\
\text { - Skin: chlorhexidine/alcohol/hypochlorous acid } \\
\text { - Mucosae: chlorhexidine/cyclodextrin + iso- } \\
\text { - flavonoids/povidone iodine } \\
\text { - Gloves+ hand washing } \\
\text { - COVID-19 protection protocol bidirectional }\end{array}$ & $\begin{array}{l}\text { Vascular events } \\
\text { - HDPH } \\
\text { - Avoid nitroglycerin paste } \\
\text { - If visual disturbance: } \\
\text { a) Stop injecting } \\
\text { b) Ophthalmological } \\
\text { referral (speed dial) } \\
\text { c) }<90 \text {-min timeframe }\end{array}$ \\
\hline \multirow[t]{2}{*}{$\begin{array}{l}\text { 3. Consent } \\
\text { - Covid-19 guidelines } \\
\text { - Procedure } \\
\text { - Complication Rx: allergic, infec- } \\
\text { tive, vascular, LOAE } \\
\text { - Hyaluronidase, "off-label"? } \\
\text { - Financial consent } \\
\text { - Photographic consent }\end{array}$} & $\begin{array}{l}\text { 6. Product layering } \\
\text { - Caution: } \\
\text { - HA over minimally biode- } \\
\text { gradable fillers } \\
\text { - Unknown filler: Ultrasound }\end{array}$ & $\begin{array}{l}\text { 9. Injection anatomy } \\
\text { - Topographical anatomy } \\
\text { - I0 markings } \\
\text { - Danger areas } \\
\text { - Choke anastomoses } \\
\text { - Pinch anatomy }\end{array}$ & $\begin{array}{l}\text { Infection } \\
\text { - Oral antibiotics } \\
\text { - Hyaluronidase } \\
\text { - Surgical drainage }\end{array}$ \\
\hline & & $\begin{array}{l}\text { 10. Technical knowledge } \\
\text { - Depth, placement } \\
\text { - Angles: } 10,30,45,90 \text { degree } \\
\text { - Speed } \\
\text { - Volume } \\
\text { - Needle vs cannula } \\
\text { - Aspiration vs movement }\end{array}$ & $\begin{array}{l}\text { Late-onset adverse } \\
\text { events } \\
\text { - Antibiotics } \\
\text { - Hyaluronidase } \\
\text { - Immunosuppressives } \\
\text { - Allopurinol, colchicine }\end{array}$ \\
\hline
\end{tabular}

Abbreviations: Rx, treatment; LOAE, late onset adverse events; LGBTQ+, lesbian, gay, bisexual, transgender and queer or questioning; HA, hyaluronic acid; IV, intravenous; SLR, single-lens reflex; ANTT, aseptic non-touch technique; COVID-19, SARS-Covid virus disease of 2019; HDPH, high-dose pulse hyaluronidase. 
Table 2 Selection Criteria

\begin{tabular}{|c|c|c|c|}
\hline Condition & $\begin{array}{l}\text { Contraindication (CI) or } \\
\text { Physician Discretion (PD) }\end{array}$ & $\begin{array}{l}\text { Timing to } \\
\text { Filler } \mathbf{R x}\end{array}$ & Suggestions \\
\hline Chemotherapy & $\mathrm{Cl}$ on $\mathrm{Rx}$ & $\begin{array}{l}>6 \mathrm{~m} \text { after } \\
\text { completion }\end{array}$ & $\begin{array}{l}\text { Immunosuppression documented } 6 \text { months after adjuvant Rx; } \\
\text { Consider psychological needs. Informed consent. }\end{array}$ \\
\hline Radiotherapy & PD & $>6 \mathrm{~m}$ & Vigilant follow-up \\
\hline Immunotherapy & PD; Postpone & & $\begin{array}{l}\text { Insistent pt with subsequent LOAEs: No systemic steroids! } \\
\mathrm{Rx}: \mathrm{AB}, \pm \mathrm{I} / \mathrm{L} \text { steroids } \\
\text { Caution: tumor - mimicking filler types (scans) }\end{array}$ \\
\hline Previous LOAE & & $\begin{array}{l}\text { I } \mathrm{m} \text { after full } \\
\text { clearance }\end{array}$ & Exclude previous trigger factors \\
\hline Acne & Pre-Rx & Clearance & $\begin{array}{l}\text { Topical: Pre-Rx entire acne area } \\
\text { Increased resistant } P \text { acnes at edge of topically } R x \text { area; No safe } \\
\text { distance }\end{array}$ \\
\hline Rosacea & Barrier Fx decreased & $\mathrm{I}-3 \mathrm{~m}$ & \\
\hline Perioral dermatitis & & 6 weeks & \\
\hline Dermatitis & Barrier Fx decreased & $\begin{array}{l}\text { I } \mathrm{m} \text { after } \\
\text { clearance }\end{array}$ & Caution: allergies, staph carriers, eczema herpeticum \\
\hline Autoimmune collagenoses & Active: $\mathrm{Cl}$ & & Check parameters; Rheumatology consult \\
\hline Rheumatoid Arthritis & Active: $\mathrm{Cl}$ & $\begin{array}{l}\text { Stable: skin test } \\
\text { before injection }\end{array}$ & \\
\hline $\begin{array}{l}\text { Systemic lupus } \\
\text { erythematosus }\end{array}$ & Active: $\mathrm{Cl}$ & $\begin{array}{l}\text { Stable: skin test } \\
\text { before injection }\end{array}$ & \\
\hline $\begin{array}{l}\text { Mixed Connective Tissue } \\
\text { Disease }\end{array}$ & $\mathrm{Cl}$ & & \\
\hline Thyroid & Hashimoto: $\mathrm{Cl}$ & & Burnt-out Hashimoto's: may treat \\
\hline Diabetes & PD & & Decreased tissue healing \\
\hline Active HSV & $\mathrm{Cl}$ & $\begin{array}{l}\text { Prophylaxis: start } \\
\text { I-day pre-Rx } \\
\text { Full } 5 \text { days of } R x\end{array}$ & $\begin{array}{l}\text { Infective until last crust disappeared } \\
\text { HSV prophylaxis pre-procedural } \\
\text { Treatment history? Resistance }\end{array}$ \\
\hline Porphyria & PD drug intolerances & & Caution: treatment of potential A/E's - drug C/l's \\
\hline Pregnancy & $\mathrm{Cl}$ & & No safety data; Medicolegal implications \\
\hline Lactation & PD & & \\
\hline Body dysmorphic disorder & PD & & Complications \\
\hline Transgender (Transitioning) & & & $\begin{array}{l}\text { Psychiatric counselling, informed consent and photo- } \\
\text { documentation } \\
\text { Hormone-induced acne, especially female to male } \\
\text { transitioning }\end{array}$ \\
\hline HIV & PD & & Full-blown AIDS: CI \\
\hline Chronic urticaria & $\mathrm{Cl}$ & & \\
\hline
\end{tabular}

(Continued) 
Table 2 (Continued).

\begin{tabular}{|l|l|l|l|}
\hline Condition & $\begin{array}{l}\text { Contraindication (CI) or } \\
\text { Physician Discretion (PD) }\end{array}$ & $\begin{array}{l}\text { Timing to } \\
\text { Filler Rx }\end{array}$ & Suggestions \\
\hline Severe allergies (multiple) & PD & $\begin{array}{l}2-4 \text { weeks } \\
\text { between }\end{array}$ & Enquire re vaccination protocols \\
\hline $\begin{array}{l}\text { Vaccinations COVID-19 } \\
\text { SARS2 }\end{array}$ & $\begin{array}{l}\text { Filler and } \\
\text { vaccination } \\
\text { (Unknown: } \\
\text { suggested 2-4 } \\
\text { weeks) }\end{array}$ & $\begin{array}{l}\text { Prophylactic lisinopril may be attempted } \\
\text { (a) in LOAE-prone patients } \\
\text { (b) before 2nd vaccination, if reaction occurred after first } \\
\text { vaccination }\end{array}$ \\
\hline
\end{tabular}

Abbreviations: $\mathrm{Cl}$, contraindicated; PD, physician discretion; $\mathrm{AB}$, antibiotics; I/L, intralesional; m, month; $\mathrm{A} / \mathrm{E}$, adverse events; LOAE, late onset adverse events; $\mathrm{AIDS}$, acquired immunodeficiency syndrome.

immunity, chronic inflammation, carcinogenesis, and the effects of antineoplastic therapy. ${ }^{2}$

Physicians should, however, consider the cumulative psychological burden of altered physical appearance, loss of identity, helplessness to change, and subsequent impact on immunity. Oncologic patients are often concerned about their appearance and fear pitying remarks from outsiders regarding their overall physiognomy. Wearing a cap or a headscarf to hide chemotherapy induced alopecia is an example of the former. Often patients are strongly insistent on maintaining regular aesthetic treatments in order to avoid the perception of suffering or losing their attractiveness. Therefore, the psychological benefits of aesthetic treatments often transcend their potential fear. ${ }^{3}$ Importantly, risks should be consented upfront.

Active chemotherapy is an accepted contraindication to fillers, with significantly delayed long-term immune changes documented 12 months post-treatment and at least 6-10 months after completing adjuvant therapy for breast cancer. ${ }^{4}$ Early recovery phases are prone to viral reactivation, with increased bacterial infections during later stages and slower recovery in smokers. ${ }^{5}$

Increasingly, antineoplastic immunotherapy is causing a unique spectrum of immune-related adverse events. Immune checkpoint inhibitors (ICI) ${ }^{6}$ remove the brake on activated T-lymphocytes, enabling T-cell attack on normal cells. LOAEs are documented after ipilimumab ${ }^{7,8}$ and cetuximab, ${ }^{9}$ and facial swelling and granulomatous reactions with protein-tyrosine kinase inhibitors. However, uneventful HA filler treatment has been described after treatment with imatinib mesylate. ${ }^{10}$

Carboxymethylcellulose-polycaprolactone, and polylactic acid fillers may induce LOAEs mimicking tumors after nivolumab (ICI), causing staging difficulties on PETCT scans. ${ }^{11,12}$

During immunotherapy, filler treatments should preferably be postponed, with vigilant follow-up in patients insisting on psychologically motivated treatments. Standard antibiotic and intralesional steroid treatment of LOAEs is permissible, while oral steroids are contraindicated due to potential interruption of immunotherapy.

The immunological effects of radiotherapy and paradoxical effects of immune stimulation or suppression vary with individual regimes. ${ }^{13}$ Although no discrete guidelines exist, it is advisable to consider post-radiotherapy patients as being immunosuppressed and to delay fillers for at least 6-12 months.

Physician discretion and vigilant follow-up are advocated in situations where fillers may offer much-needed psychological support after treatment of neoplastic disease. $^{3}$

In contrast to a 2010 study inferring chronic inflammatory or neoplastic changes due to the pro-inflammatory properties of "low molecular" HA molecules, other reports have queried the actual presence of HA fragments and highlighted varying definitions of "low molecular weight" fragments. (Table 7). ${ }^{14,15}$

A single anecdotal case has posed a hypothetical correlation between a cutaneous metaplastic synovial cyst and facial HA injections. ${ }^{16}$ However, large long-term cohort studies demonstrating extensive pharmaco-vigilance have failed to correlate neoplasia with either single or repeated facial HA filler injections.

Autoimmune Collagen Disease: Lupus, Morphea and Systemic Sclerosis 


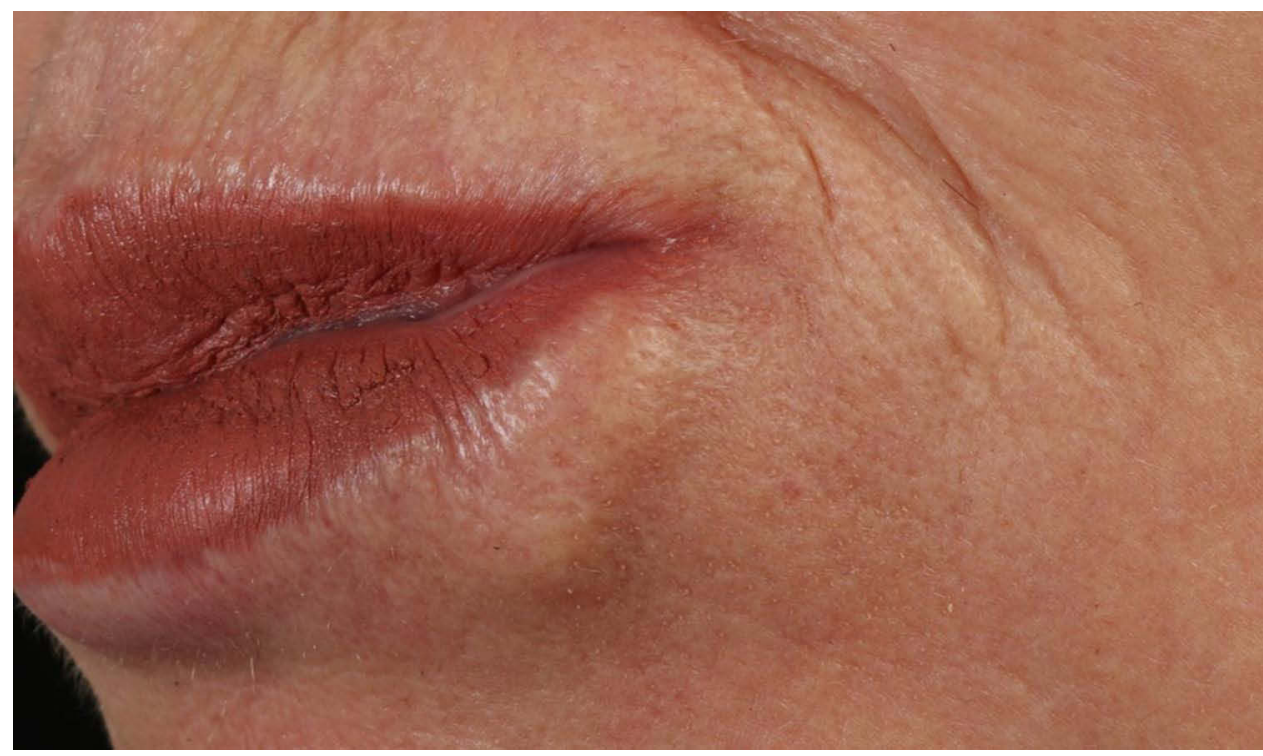

Figure I Recalcitrant LOAE in a patient with uneventful previous fillers, developing 6 months after onset of cannabis dependency Note: Image courtesy of Dr Heydenrych.

Previous recommendation has been for filler avoidance during active phases of collagen disease, whilst stable or burntout disease phases may be treated with relative safety.

Two recent literature reviews state that patients with autoimmune conditions may be safely treated with a variety of fillers. ${ }^{17,18}$ During active disease stages, we still advise against filler treatments.

\section{Recreational Drugs}

Nicotine and recreational drugs such as marijuana, cocaine, and opiates not only alter neuropsychological and pathophysiological responses but also inhibit immune function through direct and indirect mechanisms enhancing susceptibility to infections (Figure 1). ${ }^{19}$

The potential effect on tissue response, healing, and onset of adverse events should not be overlooked. The negative effect of smoking on cancer rehabilitation is well documented. ${ }^{20}$

\section{Drug Interactions}

LOAE protocols may recommend antibiotics or anti-inflammatories prone to drug interactions involving especially hepatic cytochrome P-related medications (eg, clarithromycin, erythromycin, celecoxib, diclofenac) necessitating careful documentation of prior drug intake.

Genetic Predisposition to Immune-Mediated Adverse Reactions, and Genes Within the Major Histocompatibility Complex
Upfront screening for a propensity to LOAEs, although not currently feasible, would be ideal. In addition to speculation around HLA B*08 and DRB1*03 - subtypes in immune-mediated disorders affecting women with silicone breast implants, Decates et al also examined the major histocompatibility haplotypes in 211 patients where 129/ 211 demonstrated LOAEs after fillers. A significant correlation was demonstrated between the combined presence of HLA B*08/DRB $1 * 03$ and inflammation, with an almost 4-fold increase in immune-mediated adverse events (odds ratio $=3.79,95 \% \mathrm{CI} 1.25-11.48) .{ }^{18}$

HLA subtyping poses future possibilities for preidentifying individuals at risk of delayed reactions.

Our recommendation is for avoidance of fillers in patients with this specific combination of HLA subtypes (B*08 and DRB1*03).

\section{Pregnancy and Lactation}

Medicolegally, insufficient procedural or drug-related safety data mandate against use during pregnancy, intended pregnancy, or breastfeeding. Due to the paucity of data and unpredictability of complications and their management, fillers are deemed inadvisable during pregnancy or lactation. ${ }^{21}$ Should a patient fall pregnant shortly after treatment, no specific action other than routine follow-up is needed.

\section{Previous LOAEs}

The safety and timing of re-treatment after previous 


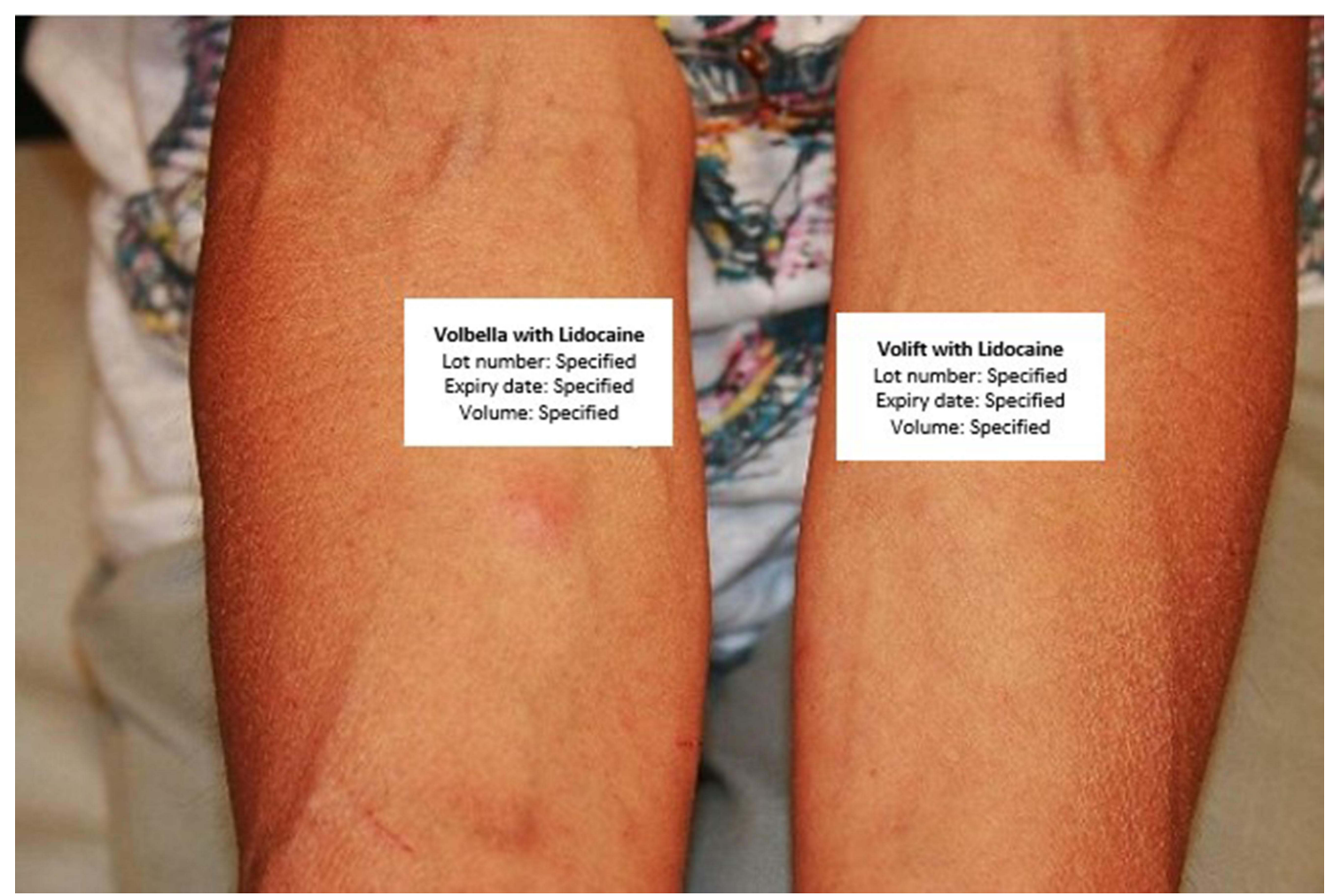

Figure 2 After I month: the test site with Volbella showed a positive reaction.

Note: Image courtesy of Dr K De Boulle.

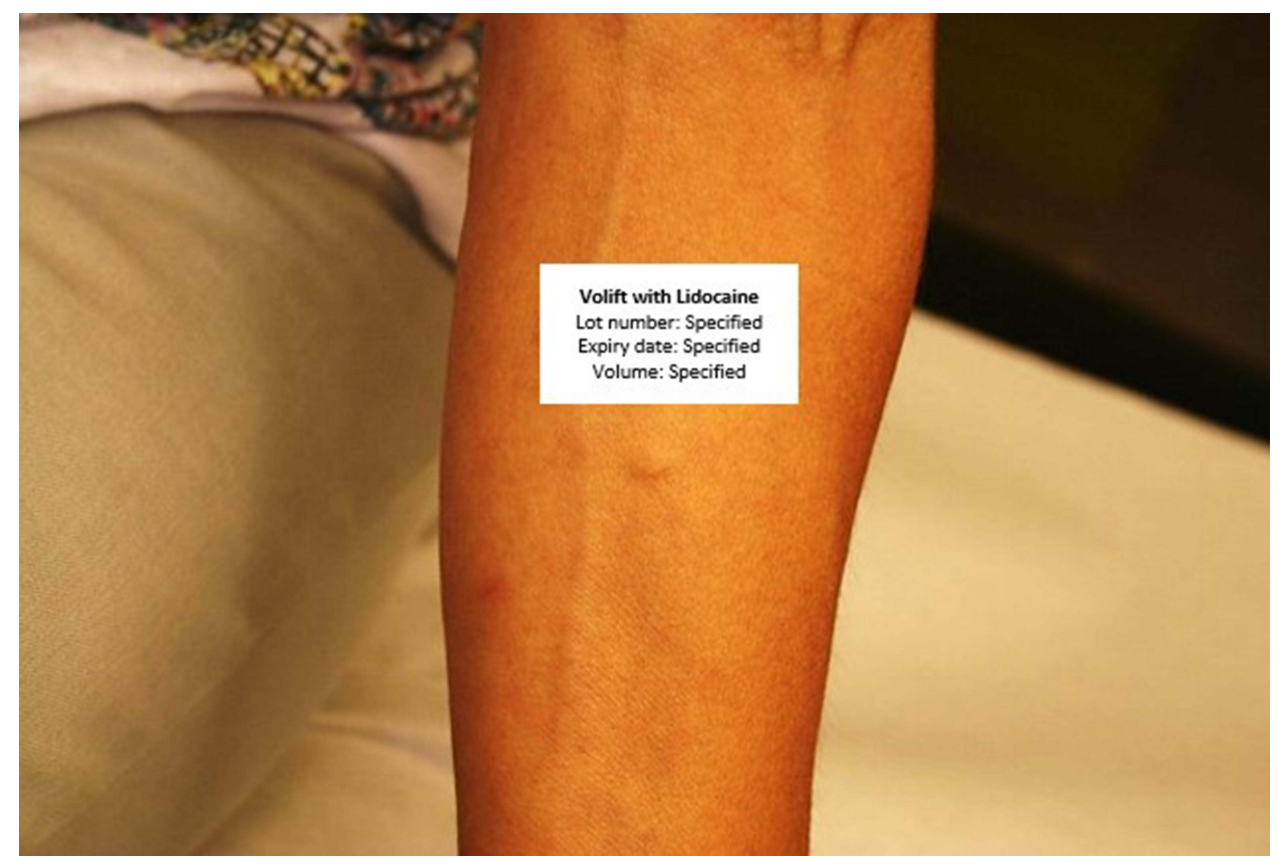

Figure 3 After 3 months: positive reaction for Juvederm Volbella and Volift. Note: Image courtesy of Dr K De Boulle. 


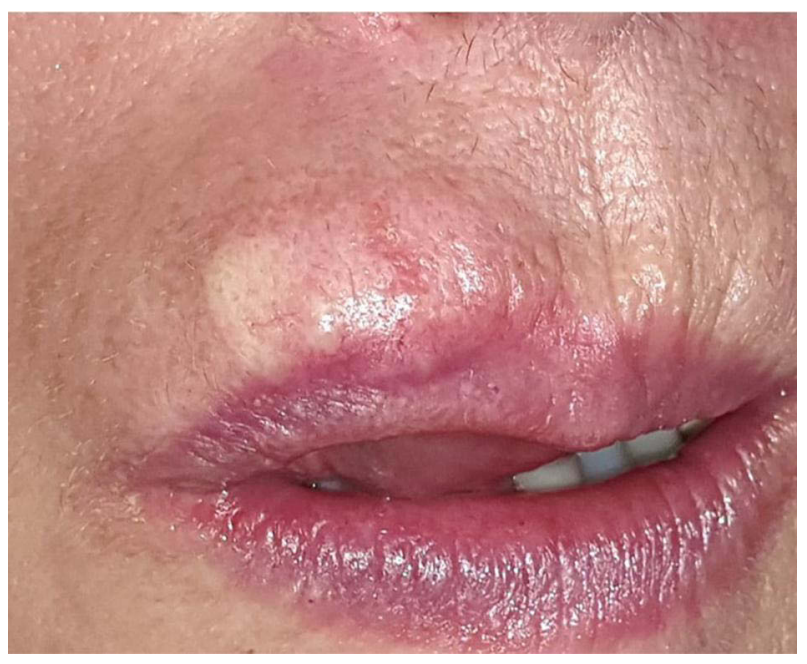

Figure 4 Artecoll granuloma (20 years) with exacerbation after Fractional resurfacing and subsequent $\mathrm{HA}$ layering.

Note: Image courtesy of Dr K De Boulle.

LOAEs is often questioned. Importantly, previous triggers such as acne, dental procedures, sinusitis, gastroenteritis, flu-like illness, vaccinations or causes of compromised skin barrier should be managed upfront. A recent review cites the majority of patients re-treated with a similar filler product having an uneventful course. ${ }^{22}$

The authors suggest at least one month between full clearance of LOAE and re-treatment to exclude transient clearance on steroids or antibiotics. For medicolegal purposes, an intradermal test with $0.1 \mathrm{ml}$ of the intended product may be performed and checked after 1 and 3 months (Figures 2 and 3).

\section{Energy-Based Devices (EBD)}

EBD treatments are best avoided in areas overlying LOAEs as they invariably impact skin barrier function and may act as external trauma triggers or induce infection in predisposed patients. Radiofrequency treatment (RF) has been documented to result in statistically significant increases in inflammatory, foreign body, and fibrotic responses associated with fillers despite histological absence of immediate thermal effect following RF (Figure 4). ${ }^{23}$ The use of microneedle RF over recently placed filler should be approached with caution. ${ }^{24}$

\section{Skin Barrier Function, Infection, and Treatment Timing} Importantly, skin barrier function may be altered for 3-4 weeks after apparent clearing of conditions such as dermatitis.
Active rosacea implies increased vascularity, impeded barrier function, and antimicrobial peptides, generally taking 12 weeks to stabilize. ${ }^{25}$ Perioral dermatitis should be pre-treated to full clearance, generally necessitating 6 weeks.

Patients with underlying Staphylococcus aureus carrier status may be treated topically with intranasal mupirocin bd $x 5$ days, alternatively topical neomycin and bacitracin, chlorhexidine, or bleach baths. ${ }^{26}$

Herpes simplex (HSV) lesions are infective until disappearance of the last crust. To prevent eczema herpeticum, particularly in patients with a history of or active atopic dermatitis, HSV is best treated prophylactically for 5 days starting one day pre-treatment, particularly when injecting close to HSV areas. Acyclovir (ACV) and related nucleoside analogs (valacyclovir or famciclovir) have long been a gold standard. However, the rapid emergence of ACV-resistant HSV, combined with increasing transplant and cancer patient numbers, mandates a careful treatment history despite this not representing the usual injectable patient cohort. ${ }^{27}$

\section{Covid Infection}

LOAEs following influenza-like viral illnesses are documented after treatment with various HA filler brands. The current global COVID-19 SARS 2 pandemic has led to similar reaction patterns, with several publications detailing LOAEs after HA fillers. ${ }^{28-30}$

The COVID-19 SARS-2 spike protein interacts with dermal angiotensin-converting enzyme receptors (ACE2) which normally regulate the homeostasis between angiotensin 2 (pro-inflammatory) and angiotensin 1 (antiinflammatory). This induces a pro-inflammatory, locoregional TH1 cascade thought to promote a CD8+T cellmediated reaction to incipient granulomas previously formed around residual HA particles. ${ }^{29}$

\section{Covid Vaccinations}

As seen in the ASIA (Autoimmune/inflammatory syndrome induced by adjuvants) syndrome, vaccinations may trigger immunological hypersensitivity cascades with subsequent LOAEs. ${ }^{31}$ Not surprisingly, LOAEs have indeed been reported after various COVID-19 SARS 2 vaccine brands. ${ }^{29}$ Multiple clinical manifestations ranging from edema, erythema, swelling and tenderness to subsequent painful, indurated plaques and nodules have been documented in patients with fillers 
placed from weeks to years before either a first or second Covid vaccination. ${ }^{30}$

Evolving COVID-19 vaccination protocols may well become one of the most common triggers of subsequent HA filler-associated LOAE, with the triad of increasing filler use, escalating COVID-SARS-2 infection rates and progressive vaccine roll-out recently cited as potentially portending a perfect storm. ${ }^{29}$

Interestingly, ACE inhibitors such as lisinopril have anecdotally been found beneficial in reducing vaccination-induced LOAEs, with lisinopril proposed as pre-vaccination medication in patients prone to LOAEs after HA fillers, or having developed LOAEs following first vaccinations. ${ }^{32}$ Currently, no controlled study is available to prove either large-scale benefit or the benefit following non-HA fillers. As cited in recent publications, oral corticosteroids constitute initial one-month therapy for Covid vaccination-related LOAE therapy for Covid vaccinationrelated LOAE. ${ }^{29,30}$

\section{Patient Expectations and Psychological Screening}

Body dysmorphic disorder (BDD) often presents with cosmetic complaints and higher pre-procedural expectations (Table 3). Psychopathology or unrealistic expectations regarding enhanced quality of life (QOL), self-esteem, social interactions or facial beauty should be excluded upfront due to decreased procedural satisfaction. ${ }^{33}$

Patient questionnaires may serve as valuable screening tools. Concerning answers to the questions in Figure 5 merit completion of a more extensive BDD questionnaire or referral for psychological evaluation (Figure 5). ${ }^{34}$

\section{Assessment}

\section{Generation}

Baby boomers (in their 60s) and Gen Zs (born 1994-) currently comprise the largest aesthetic market segments, mandating an understanding of specific needs. ${ }^{35}$ Aesthetic education of younger generations also bears long-term implications for future patient loyalty. The expert injector's role lies in communicating insightful facial analysis despite the increasing challenge of selfies, photographic distortion and social media pressure. A systematic analysis of all facial angles, both in repose and animation, helps to establish expertise through irrefutable clinical logic.

\section{Social Media and Aesthetic Self-Perception}

Obsessive selfie-taking, classified by the American

Table 3 Body Dysmorphic Disorder (BDD)

\begin{tabular}{|l|l|}
\hline Classification & Obsessive-compulsive and related disorders (DSM-5) \\
\hline Diagnostic criteria & $\begin{array}{l}\text { Repetitive behaviors or mental acts, inappropriate use of cosmetic treatments } \\
\text { Significant psychosocial distress and functional impairment }\end{array}$ \\
\hline Incidence & $\begin{array}{l}1.7-2.2 \% \text { of general population } \\
\text { High rates of suicidality }\end{array}$ \\
\hline Age of onset & More common in older adolescents; Mean age of onset $=16$ yrs \\
\hline Symptoms & $\begin{array}{l}\text { Commonly present with cosmetic complaints and higher pre-procedural expectations } \\
\text { Preoccupation with seemingly insignificant physical concerns } \\
\text { Worrying about appearance }>\text { I h/day } \\
\text { Reassurance- seeking behavior } \\
\text { Mental comparisons to others }\end{array}$ \\
\hline Consultation & $\begin{array}{l}\text { Repetitive mirror checking } \\
\text { Excessive grooming } \\
\text { Skin picking } \\
\text { Not listening }\end{array}$ \\
\hline Management & $\begin{array}{l}\text { Manage upfront } \\
\text { BDD questionnaire } \\
\text { Psychology referral with pre-referral conversation } \\
\text { Be specific regarding perceived patient behaviour }\end{array}$ \\
\hline
\end{tabular}

Note: Data from Krebs et al. ${ }^{34}$ 


\section{BDD Screening Questions}

1. Are you frequently worried about your appearance and wish that you could do so less often?

2. Can you identify specific appearance concerns?

3. Do you think about your appearance for less than an hour, between one to three hours or more than 3 hours per day?

4. Does your appearance affect your life, and if so, in which way?

5. Does your appearance impact your work or social life?

6. Have you previously undergone aesthetic procedures, and if so, were you happy with the results?

7. Would you consent to us contacting your previous aesthetic practitioner(s)?

8. Do you think there might be an emotional component to your elective treatment of choice?

9. Could you accept that your desired treatment may not have the exact outcome you anticipate?

10. Have you ever been counselled or treated for BDD?

Figure 5 Valuable BDD screening questions.

Note: Data adapted from Krebs et al. ${ }^{34}$

Psychiatric Association as a mental disorder associated with low self-esteem, is ascribed to social competition, attention-seeking, mood modification, self-confidence and social conformity, consequently initiating the development of a psychometric Selfitis Behavior Scale (SBS). ${ }^{36}$

Selfie-filters may encourage unrealistic expectations through complexion enhancement and altered features such as erased nasolabial folds, tighter jawlines, and bigger lips. Furthermore, normalization of pouting poses has blurred the boundaries between resting and dynamic lip proportions, complicating realistic volume expectations. Only 60-65\% of real-world images are differentiated from manipulated images, further encouraging manipulation. ${ }^{37}$

Importantly, social media has significantly altered the concept of patient confidentiality, with patients increasingly keen to publicize treatment experiences.

The current COVID-SARS2 pandemic has fuelled further perceptual change as remote living and working have forced individuals to view themselves on-screen, unedited, in motion and at the mercy of short focal length webcams. The resulting "zoom face" inevitably depicts a more rounded face, wider set eyes and broader nose, creating a flawed representation of reality which patients struggle to process. ${ }^{38}$

\section{Ethnicity}

Asian and African beauty concepts may differ fascinatingly from Caucasian ideals, with perceptions increasingly influenced by the advent of social media and "beauty influencers" (Table 4). ${ }^{39}$ Whilst the traditional African beauty concept has shifted to more Westernized ideals, with an increasing desire for lower body mass and paler, yellowish skin tone, Chinese aesthetic patients demonstrate a strong desire for retained ethnic identity. A Singaporean study comparing Caucasian and Chinese aesthetic patients demonstrated that Chinese patients were younger and more likely to seek correction or more obvious changes than Caucasian patients. On multivariate analyses, powerful predictors for proceeding with non-invasive facial treatments included rejuvenation rather than correction as a goal, an expectation of an immediate result, and prior aesthetic treatments. ${ }^{40}$

The expert injector should understand not only universal, cross-cultural beauty ideals, but grasp applicable ethnic nuances.

\section{Asian}

Asian faces have unique facial proportions, beauty concepts, aging stigmata, and cosmetic demands. ${ }^{40}$ The frequent need for centro-facial treatment with higher injection volumes merits highly specialized skills and carries a higher risk of intravascular embolic events. 
Table 4 Ethnicities: Features and Management

\begin{tabular}{|c|c|c|c|c|}
\hline & Asian & Caucasiaon & African & Indian \\
\hline $\begin{array}{l}\text { Skull (anterior } \\
\text { and lateral) }\end{array}$ & $\begin{array}{l}\text { Wide, short, flatter face } \\
\text { Wider bitemporal, bi- } \\
\text { zygomatic, bigonial } \\
\text { Retruded forehead } \\
\text { less anterior projection } \\
\text { Retruded pyriform margin }\end{array}$ & $\begin{array}{l}\text { Longer, narrower } \\
\text { skull } \\
\text { More projected }\end{array}$ & $\begin{array}{l}\text { Post-bregmatic depression } \\
\text { Maxillary hypoplasia } \\
\text { Prominent zygoma } \\
\text { Microgenia }\end{array}$ & $\begin{array}{l}\text { Less vertical height } \\
\text { Rounder, less oval face } \\
\text { Increased forehead height } \\
\text { Smaller chin and lower face } \\
\text { More convex than Caucasian }\end{array}$ \\
\hline $\begin{array}{l}\text { Orbits } \\
\text { Eyes }\end{array}$ & $\begin{array}{l}\text { Greater intercanthal width } \\
\text { Shallow orbits } \\
\text { Smaller eye aperture width } \\
\text { Epicanthal folds } \\
\text { Puffy upper eyelids }\end{array}$ & Angular; "aviator" & $\begin{array}{l}\text { Rectangular } \\
\text { Shorter horizontal } \\
\text { Proptosis, rounded lat canthus, } \\
\text { early scleral show }\end{array}$ & Larger eyes, wider set \\
\hline $\begin{array}{l}\text { Interorbital } \\
\text { distance }\end{array}$ & Intermediate & Narrow & Wider, no hypertelorism & Wider \\
\hline Lips & $\begin{array}{l}\text { Protruded } \\
\text { Fuller } \\
\text { Prominent upper lip }\end{array}$ & $\begin{array}{l}\text { Aging: rhytides above } \\
\text { vermillion }\end{array}$ & $\begin{array}{l}\text { Larger all dimensions } \\
\text { Protruded } \\
\text { Equal upper and lower lip } \\
\text { volume } \\
\text { Aging: wrinkling on vermillion } \\
\text { Bimaxillary prognathism }\end{array}$ & Good volume and projection \\
\hline Nose & $\begin{array}{l}\text { Flat dorsum, wide base, } \\
\text { less tip projection }\end{array}$ & $\begin{array}{l}\text { Leptorrhine } \\
\text { Narrower nasal } \\
\text { opening } \\
\text { More projection } \\
\text { Straighter nasal } \\
\text { profile } \\
\text { More acute } \\
\text { columella-labial angle } \\
\text { Less flared ala }\end{array}$ & $\begin{array}{l}\text { Platyrrhine } \\
\text { Lower and flatter } \\
\text { Wide base, less tip projection } \\
\text { Alar flaring }\end{array}$ & $\begin{array}{l}\text { Wider } \\
\text { Length: } \\
\text { > Asian } \\
\text { < Caucasian } \\
\text { Width: } \\
\text { < African/Asian } \\
\text { > Caucasian }\end{array}$ \\
\hline $\begin{array}{l}\text { Skin } \\
\text { Aging }\end{array}$ & $\begin{array}{l}\text { More melanin } \\
\text { Delayed actinic damage } \\
\text { Pigmentary aging concerns } \\
\text { Delayed wrinkling and } \\
\text { sagging }\end{array}$ & $\begin{array}{l}\text { Less melanin } \\
\text { More photoaging } \\
\text { Upper lip rhytides }\end{array}$ & $\begin{array}{l}\text { More melanin Delayed aging: } \\
\text { 5th-6th decade } \\
\text { Pores: less, deeper } \\
\text { Early scleral show } \\
\text { Submental fat with aging }\end{array}$ & $\begin{array}{l}\text { More melanin } \\
\text { Thicker skin } \\
\text { Delayed photoaging Malar volume } \\
\text { loss and jowls }\end{array}$ \\
\hline Concerns & $\begin{array}{l}\text { Masseters (facial slimming) } \\
\text { Nasal shape } \\
\text { Tear trough }\end{array}$ & $\begin{array}{l}\text { Rhytides } \\
\text { Photodamage } \\
\text { Sagging }\end{array}$ & $\begin{array}{l}\text { Scleral show } \\
\text { Sagginess }\end{array}$ & $\begin{array}{l}\text { Early tear trough deformity } \\
\text { Periorbital hyperpigmentation } \\
\text { Sagging of thicker soft tissue on } \\
\text { small bony framework }\end{array}$ \\
\hline Desires & $\begin{array}{l}\text { Structural needs } \\
\text { Oval facial shape } \\
\text { 3-dimensionality } \\
\text { Nasal projection } \\
\text { Unblemished skin }\end{array}$ & $\begin{array}{l}\text { Photodamage } \\
\text { Sagging }\end{array}$ & Skin quality/tone & $\begin{array}{l}\text { Aging: malar volume loss and jowls } \\
\text { Lift lateral vectors } \\
\text { Conservative volume medial zones }\end{array}$ \\
\hline
\end{tabular}

Note: Data from Samizadeh et al, ${ }^{40}$ Kapoor et al, ${ }^{41}$ and Liew. ${ }^{87}$ 
Indian

The Indian face is particularly prone to developing early periorbital hyperpigmentation and infraorbital hollowing, with tear trough deficiency the most common filler request between 20 and 40 years. $^{41}$ Malar volume loss and jowling are common in older individuals, with excess medial soft tissue on a relatively smaller midface mandating initial treatment of lateral vectors to create adequate lift without excess medial volume. The shorter, wider lower face requires 3-dimensional correction and chin augmentation to achieve optimal facial height and the desired oval shape.

\section{African}

Despite escalating demand, few discrete guidelines exist for African phenotypes. Key considerations include a tendency to scarring, keloids or post-inflammatory hyperpigmentation (PIHP). ${ }^{39}$ Mild and transient hyperpigmentation after nasolabial fold HA fillers in Fitzpatrick Skin Types (FST) IV-V1 is cited in $2-17 \%$ of patients ( $6 \%$ of injection sites). Serial punctures, superficial injection depth and fast injection speed predispose to PIHP. Whilst a $27 \mathrm{G}$ needle should pose no significant risk of PIHP or keloid formation, a test area with a small 31/33-gauge needle is suggested when in doubt. Keloid tendency is linked to chromosome band 7p11 and the EGFR gene. ${ }^{42}$

\section{LGBTQ+ Population}

When performed with a clear understanding of male and female features and desired outcomes, facial procedures may greatly enhance overall QOL. Hormonal therapy, especially whilst transitioning from female to male, may induce acne which should be optimally treated before attempting fillers. ${ }^{43}$

Clinic staff should be trained in using preferred pronouns and identifiers when addressing transgender patients, whilst intake forms should request "gender" rather than "sex" and include a write-in option for "other."

\section{Facial Dynamics}

Insightful understanding of functional anatomy, synergistic and antagonistic muscle balance and both the direct and indirect effects of fillers are essential for natural dynamic outcomes. These principles also underlie the rehabilitation of facial palsy through injectables. ${ }^{44,45}$

Filler placement may modify muscle behaviour through:

- Stretching muscles to improve tensile strength.
- Expanding the submuscular aponeurotic system (SMAS).

- Providing a mechanical block via intramuscular injection.

- Inducing resistance or support through differential placement above or below the muscle.

\section{Consent}

Although rare, the potential for allergic reactions, infection, vascular incidents, visual loss, and LOAEs must be stipulated on consent forms and explicitly discussed with the patient. ${ }^{46}$ Particular care should be exercised when consenting patients with cancer, on antineoplastic treatment or BDD. Importantly, to circumvent treatment delays, upfront consent should be obtained for managing potential complications. Additionally, in certain countries, the aesthetic use of hyaluronidase is off-label and should be clarified. ${ }^{47}$

The Covid-era has necessitated a new subset of regulations, as well as the initiation of conversation around potential vaccination sequelae. As cutaneous implications of both COVID-19 infection and vaccination emerge, cosmetic patients may benefit from a discussion around COVID-19 vaccine-related planning as a part of pre-procedure counselling for dermal fillers. In the absence of final data, we provisionally suggest waiting 2 to 4 weeks between filler injections and vaccination, with an even longer window in patients with a higher risk profile for developing reactions. ${ }^{32}$

Upfront financial consent remains mandatory.

\section{Product \\ Reversibility}

The widespread use of HA fillers is driven by the unparalleled advantage of reversibility through hyaluronidase (Table 5). Despite a consensus paper advocating hyaluronidase for calcium hydroxylapatite $(\mathrm{CaHa})$-induced vascular occlusion due to its anti-edematous and antiinflammatory properties, it does not dissolve the culprit. While a recent proof-of-concept study has demonstrated potential reversibility of CaHA through intralesional sodium thiosulfate (STS), ${ }^{48}$ optimal injection concentration, treatment ratio, time to onset, ability to pass through intact vessels, and treatment efficacy for established nodules are still unknown. ${ }^{49,50}$

A human cadaver study has demonstrated a very limited in vitro potential of STS to dissolve intraarterial $\mathrm{CaHa}$ after submerging CaHa-filled arterial segments in varying concentrations of STS. ${ }^{50}$ 
Table 5 Hyaluronidase Safety Aspects

\begin{tabular}{|l|l|l|}
\hline Incidence & $\begin{array}{l}\text { Local reactions } \\
\text { Urticaria, angioedema } \\
\text { Anaphylaxis }\end{array}$ & $\begin{array}{l}0.05-0.69 \% \\
<0.1 \% \\
\text { Rare }\end{array}$ \\
\hline Relative C/I & Wasp/bee sting allergy & Consider antibiotics 2-7-days \\
\hline Drug interactions & Furosemide, benzodiazepines, a-adrenergics, phenytoin & Steroids \\
\hline Antagonists & NSAID's, antihistamines, Vit C, AOX's, aspirins & \\
\hline Pre-Rx & Infective/Inflammatory nodules & \multicolumn{2}{|l}{} \\
\hline Intradermal test* & $\begin{array}{l}\text { Positive: }>\text { 8mm wheal + flare at 30 min } \\
\text { Test not indicated if retinal artery occlusion/intravascular emergency }\end{array}$ \\
\hline Post-Rx observation & I-2 Hours observation in - clinic recommended & \\
\hline
\end{tabular}

Note: *Not indicated in the event of intravascular or ophthalmic events. Data from Cavallini et al. ${ }^{88}$

Table 6 Hyaluronidase Practical Aspects

\begin{tabular}{|l|l|l|}
\hline Consent & \multicolumn{2}{|l|}{ Mandatory informed consent: aesthetic use may be off-label; check country-specific recommendations } \\
\hline Diluent & Saline, bacteriostatic saline, water & \multicolumn{2}{|l|}{} \\
\hline Dilution & Eg I-10 mL/I500 IU & Immediate \\
\hline Timing & Onset of action & 2 minutes \\
& T $1 / 2$ & 48 hours \\
& Duration of action & 48 hours \\
& Recovery time endogenous HA & $21 / 2$ minutes \\
\hline Dosage & Serum half-life & $4-40$ IU/0.I mL HA \\
& Nodules & HDPH: $500-1500$ IU hourly \\
& Vascular events & Higher than standard treatment doses \\
\hline Technical aspects & Endogenous HA degradation & \\
& Massage to increase contact & \\
\hline
\end{tabular}

Note: Data from King et al ${ }^{89}$ and Rauso et al. ${ }^{90,91}$

Abbreviation: $\mathrm{HDPH}$, high dose pulse hyaluronidase.

\section{Table 7 Definitions}

\begin{tabular}{|l|l|l|}
\hline High molecular weight & $>500 \mathrm{kD}$ & Anti-inflammatory \\
Low molecular weight & $10-500 \mathrm{kD}$ \\
Oligosaccharides & $<10 \mathrm{kD}$ & Pro-inflammatory \\
\hline
\end{tabular}

\section{Hyaluronidase: Practical Aspects}

A 3-fold difference has been cited in the required number of hyaluronidase units per HA volume, with dissolution times varying from 2 to 16 minutes per $0.1 \mathrm{~mL}$ aliquot. This underscores the need for knowledge regarding the
Table 8 HA Filler Degradation

\begin{tabular}{|c|c|c|}
\hline $\mathrm{HA}$ & $\begin{array}{l}\text { Enzymatic: } \\
\text { Hyaluronidases } \\
\text { - ROS } \\
\text { - Superoxide, } \\
\text { peroxynitrite } \\
\text { - Various injury } \\
\text { models }\end{array}$ & $\begin{array}{l}\text { HYAL I +2 } \\
\text { Endo- } \beta \text {-N-acetyl-D- } \\
\text { hexosaminidase splits disaccharide } \\
\beta-I, 4-\text { glycosidic bonds } \\
\text { - ROS: Induced by cell stress, UV, } \\
\text { infrared, pollution }\end{array}$ \\
\hline BDDE & \multicolumn{2}{|c|}{ Degraded to glycerol + succinic acid } \\
\hline $\begin{array}{l}\text { Cell-surface } \\
\text { R binding }\end{array}$ & \multicolumn{2}{|c|}{$\begin{array}{l}\text { CD } 44 \text { binds large fragments (anti-inflammatory) } \\
\text { TLR's binds small HA fragments (pro-inflammatory) }\end{array}$} \\
\hline
\end{tabular}

Note: Data from De Boulle et al. ${ }^{92}$

Abbreviations: ROS, reactive oxygen species; Hyal, hyaluronidase; UV, ultraviolet; TLRs, Toll-like receptors. 
efficacy of locally available hyaluronidase on preferentially used HA products (Table 6). ${ }^{51}$

\section{Product Characteristics}

Molecular Weight, Inflammatory Response and Autoimmunity

Although HA has been cited as a potential trigger factor for the ASIA syndrome, recent publications maintain that carbohydrates induce poor antibody responses due to their antigenic incapacity to stimulate $\mathrm{T}$ cell responses (Table 7). Carbohydrates preferentially bind to membrane receptors such as immunoglobulins to induce clustering and primary B cell activation, stimulating production of low affinity, short-living IgM, and no induction of memory effect in the absence of $\mathrm{T}$ cells. $^{52,53}$

Conversely, bacteria act as potent activators of the TLRs $(1,4,5,7,9)$ to induce inflammation, innate immunity, and non-agent-specific autoimmunity (Table 8). This underlines the critical importance of aseptic technique in avoiding late-onset inflammatory and immune sequelae. ${ }^{31,54}$ In genetically predisposed patients or specific HLA types, inflammasomes are triggered, possibly through an adjuvant role of ionized molecules.

Importantly, acne is present in $10 \%$ of the population. Cutibacterium acnes (C.acnes) has a strong immunostimulatory capacity, is found in all stages of acne, and binds to the cytoplasmic nucleoside-binding oligomerization domain-like (NOD-like) receptors to induce inflammasomes and opportunistic infections, thus stimulating both innate and adaptive immune responses. ${ }^{55,56}$ The "safe injection distance" from individual acne lesions is currently unknown and adequate pre-treatment is mandatory.

\section{Product Layering}

Whilst Alijotas-Reig et al initially posed the increased risk of immune-mediated adverse reactions after consecutive injection of different fillers, a subsequent review of 260 cases found no increased risk of local or systemic reactions after repeated injections of different fillers in the same or different sites. When occurring, however, they were more likely to become chronic, systemic, and severe. $^{31}$

Layering fillers over late or minimally biodegradable products is still deemed inadvisable due to the initial filler being teased into reactivity, which may be histologically proven. ${ }^{57,58}$

In cases of unknown previous fillers, and to determine the precise nature of fillers, ultrasound may offer a valuable diagnostic tool. ${ }^{59,60}$

\section{Injection Depth and Immunological Response}

Despite questions posed around the differential immunological response with filler depth and subsequent impact on immunologically induced LOAEs in the Covid-era, no data is currently available for risk stratification of intradermal vs deep tissue injections.
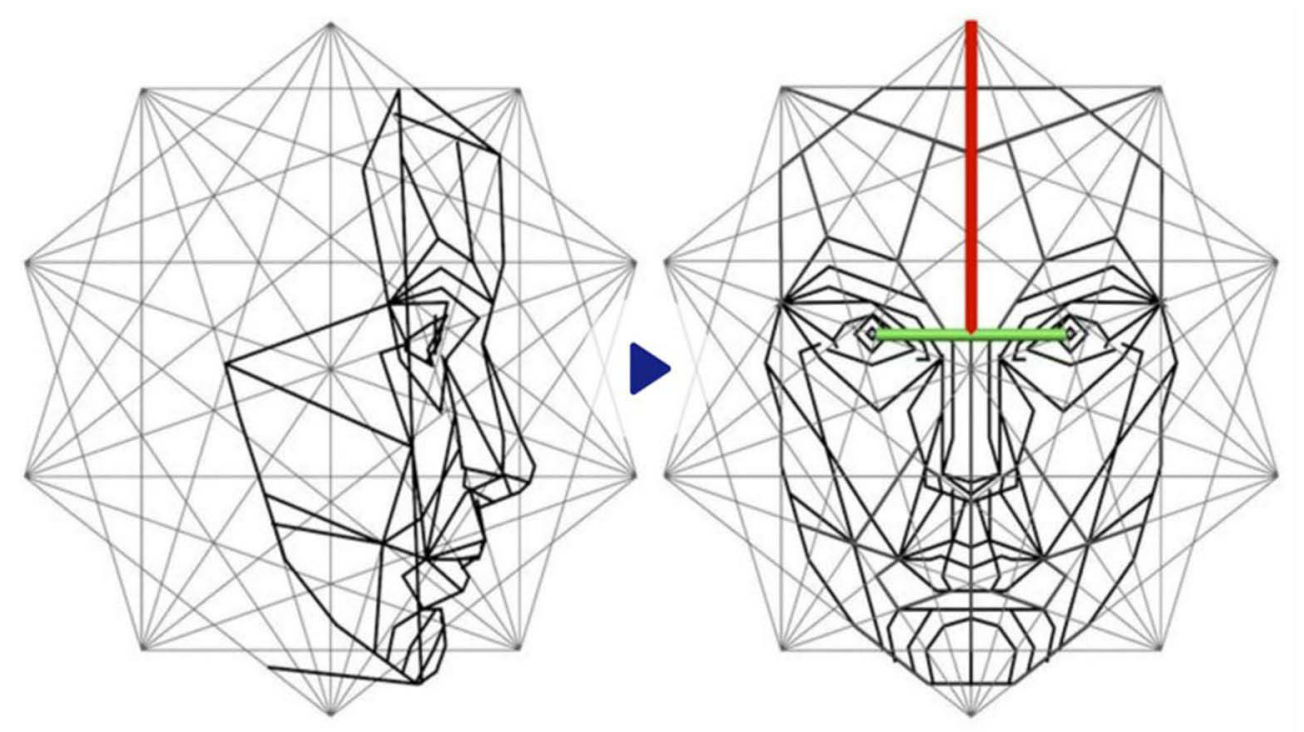

Figure 6 Frankfort horizontal plane vs natural head position. Note: Image courtesy of Woodrow Wilson . 

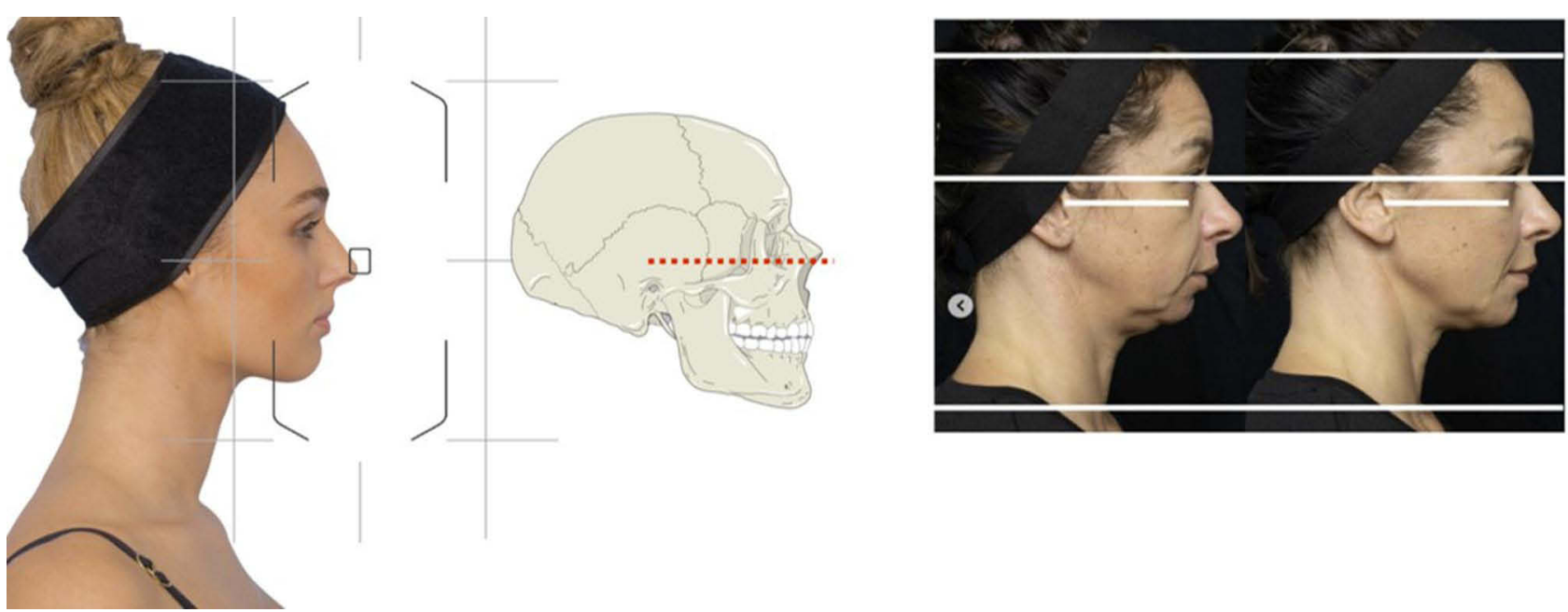

Figure 7 Illustration of the Frankfort horizontal plane, which often differs from natural head position, as viewed through a camera grid, superimposed on a skull and translated into pre-and post-photography.

Note: Image courtesy of Woodrow Wilson.

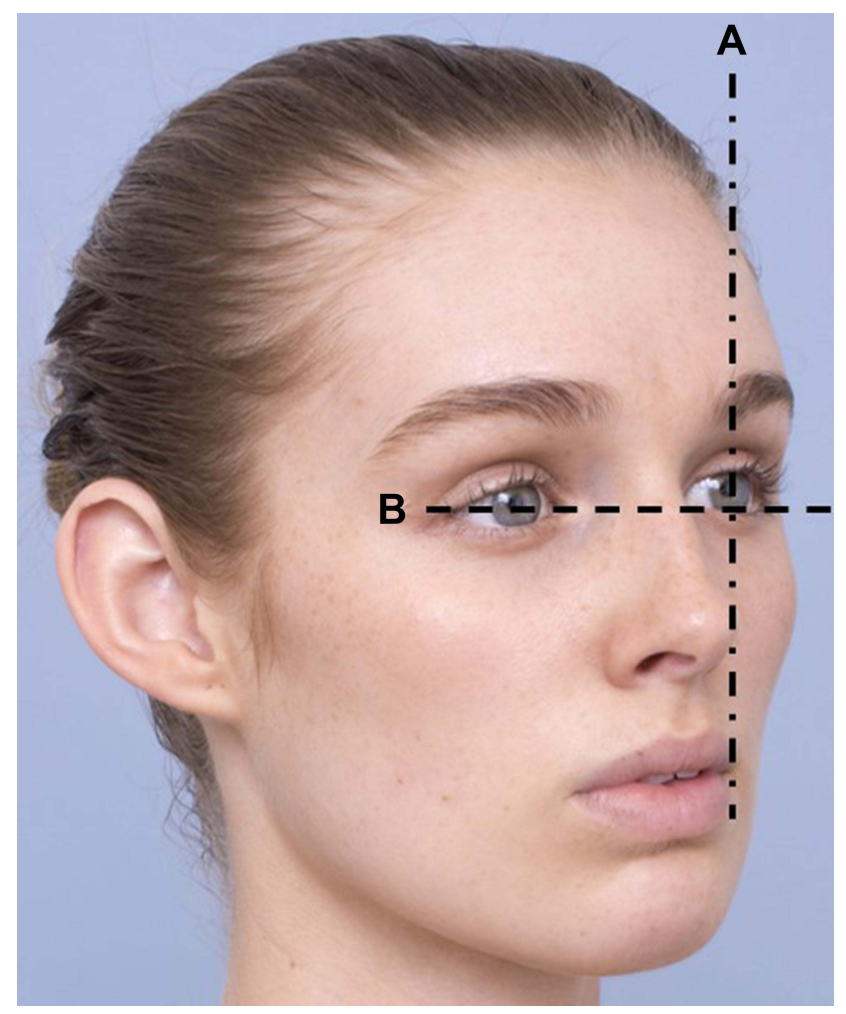

Figure 8 Shooting oblique view: (A) Align nasal tip to mid-pupil; (B) rotate head until all 4 canthi are visible.

Note: Image courtesy of Woodrow Wilson.

\section{Procedure}

Photography

Consistent Positioning

Accurate clinical photography, at rest and in animation, is vital for facial analysis, learning curves, and medicolegal purposes. Common consistency pitfalls include inaccurate positioning in the lateral and oblique views, which are avoidable by adhering to basic tenets. Position accurately for lateral views by using the Frankfort Line, thus also facilitating correct angulation for oblique views, in which all 4 canthi should be visible (Figures 6-8).

\section{Photographic Distortion}

Due to photographic distortion, mobile photos are inadequate for clinical use.

Selfies taken from a distance of 12 inches increase nasal size by $30 \%$ in males and $29 \%$ in females, with distortion of the perceived ratio of nasal breadth to bizygomatic width and inaccurate 3-dimensional appearance. Images taken at standard portrait distance render accurate proportions (Figure 9). ${ }^{61}$

Further studies are needed to establish the role of frequent selfies in increased patient dissatisfaction, and the impact of selfie distortion on future medical decisions. ${ }^{62}$ Recently, the COVID-SARS -2 pandemic has provoked a surge in patients citing their appearance on virtual platforms as the reason for seeking care, particularly concerning acne and wrinkles. ${ }^{38}$ The patient is now also the viewer!

When available, computerized photography systems may add additional consistency and finesse to accurate and academic documentation. 


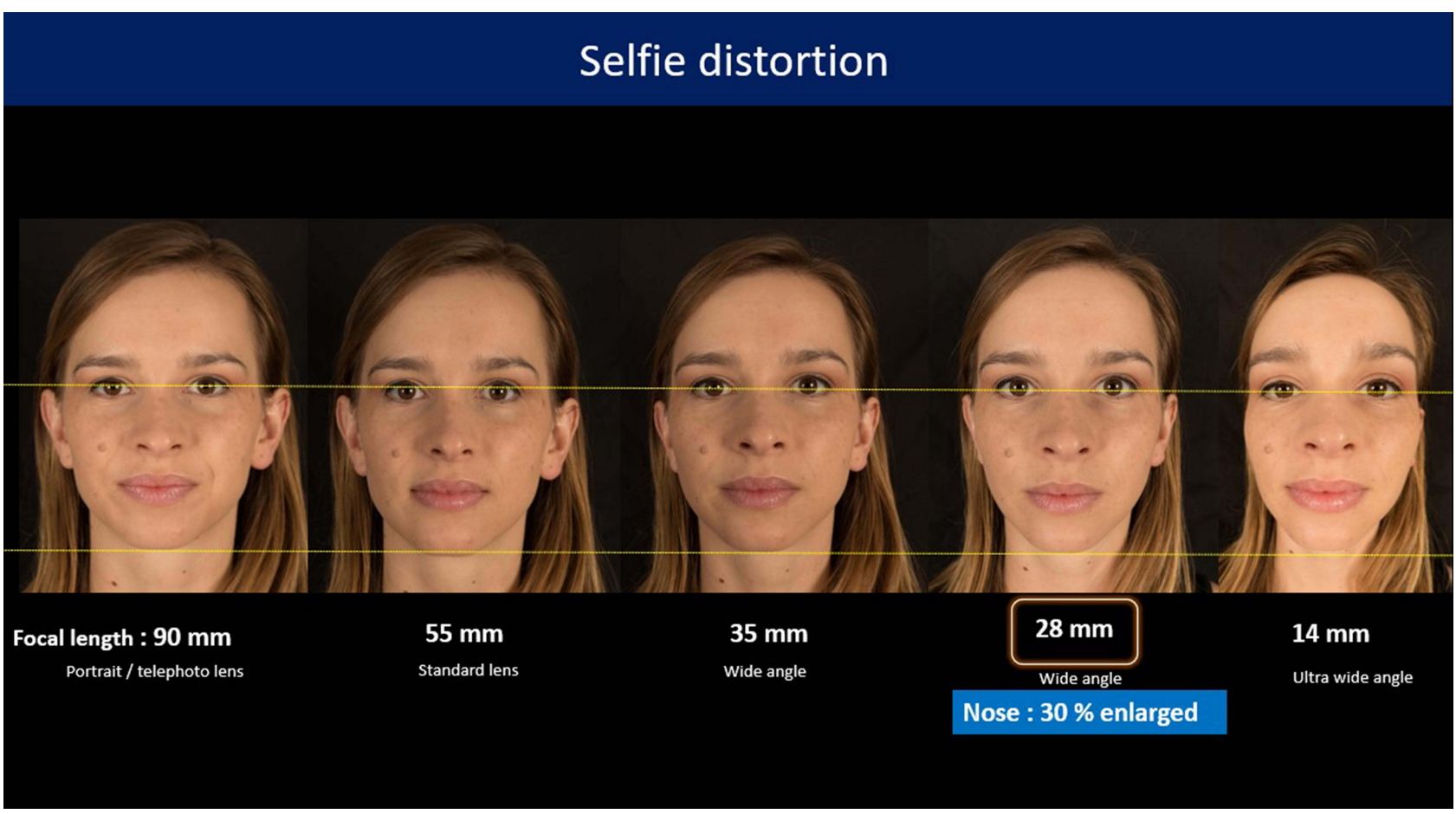

Figure 9 Selfie distortion: the effect of focal length, illustrating wide angle $(28 \mathrm{~mm})$ distortion as seen with mobile photography. Note: Image courtesy of Dr Heydenrych.

\section{Procedural Planning and Aseptic Technique Aseptic Non Touch Technique (ANTT)}

Vigilant aseptic technique is critical in the light of normal non-sterile office circumstances. Most sterility breaches have been proven to occur during the initial procedural phase, mandating pre-planning of product, volumes, and instruments of choice. ${ }^{47,63}$

\section{Mucosal Cleansing Agents}

Whilst chlorhexidine has previously been widely regarded as a good oral antiseptic, the Covid-era has raised new challenges. Preferred alternatives include Na hypochlorite, $1 \%$ peroxide, povidone-iodine, cyclodextrin, and succinic acid, with routine oral rinses $(2 \times 30$ seconds $)$ before fillers to decrease viral load. ${ }^{64,65}$

\section{Anatomy}

Intravascular injections, with consequences ranging from tissue necrosis to blindness, constitute the most feared injectable complications. Whilst topographical vessel course is varied ("x and y" axes in graph analogy), vessel depth (" $z$ " vector) is far more predictable, thus bearing great significance in avoiding filler embolism. "Injection anatomy" commonly refers to surface markings in relation to the depth of underlying vital structures.
For effective localization of adjacent vasculature, topographical points are best marked with the patient in the upright position. Important pre-procedural markings may be seen in Figures 10-12 and discussed in Table 9.

\section{Facial Artery Course}

The facial artery (FA) crosses the mandible at the antegonial notch just anterior to the anterior border of the masseter, before traveling superomedially, lateral to the modiolus, towards the piriform fossa. Between the risorius and zygomaticus major, it lies coiled and unprotected by muscle cover ("naked"), meriting injection caution. A second naked area lies superolateral from the mouth corner, medial to levator anguli oris (LAO), where the superior labial artery arises from the facial artery. The FA more frequently runs medial to the NLF, starting $1.7 \mathrm{~mm}$ medial in the lower portion, crossing beneath the fold at a depth of $5 \mathrm{~mm}$ at the superior third, and eventually reaching a point $3.2 \mathrm{~mm}$ lateral to the nasal ala (Figure 13).

\section{Pinch Anatomy}

Pinching with the non-dominant hand may serve as injection guide for avoiding inadvertent intravascular placement during temporal fossa injections through altering the tissue layer (Table 10). ${ }^{67}$ 


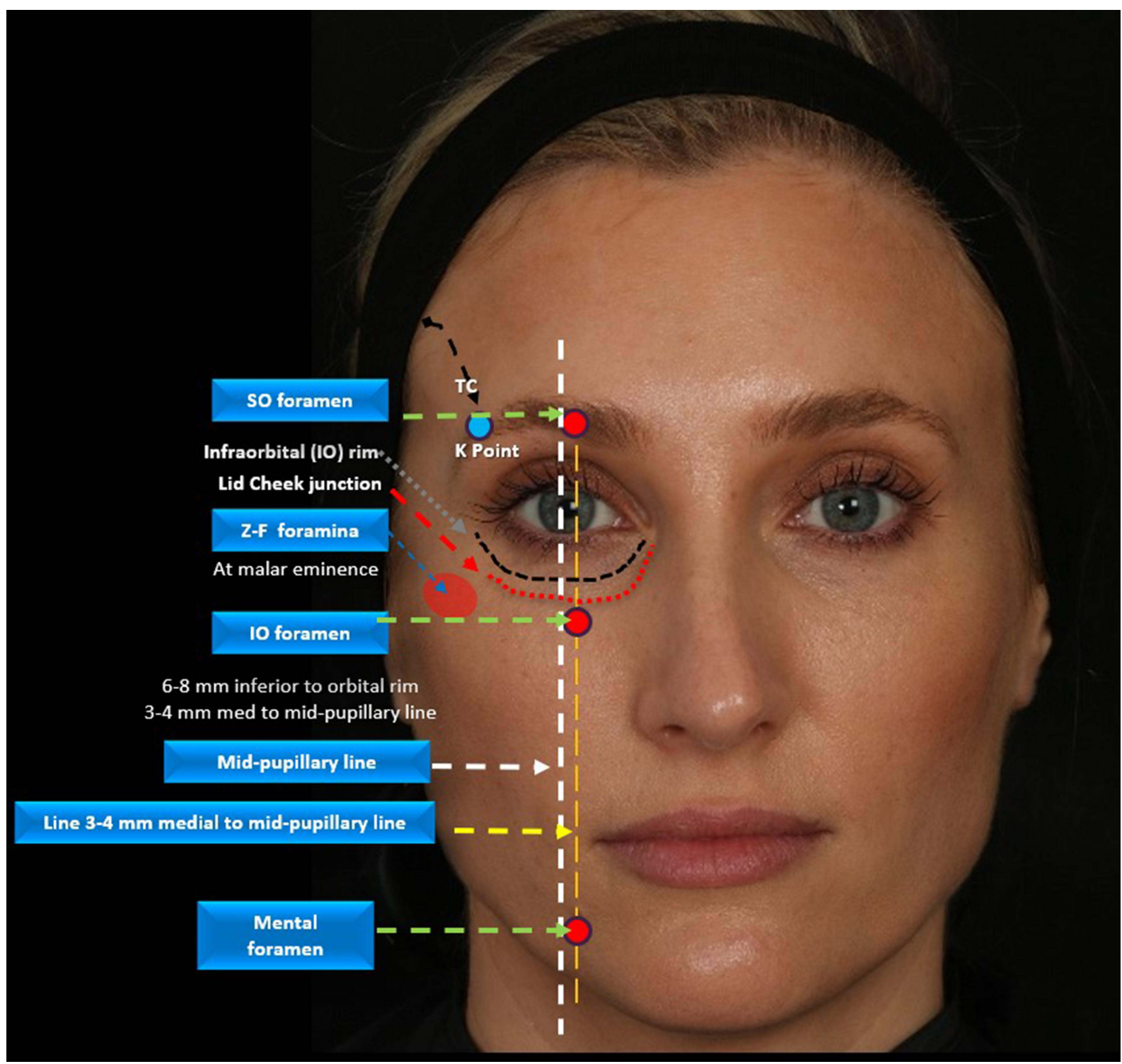

Figure 10 Topographical markings of foramina in anterior view.

Note: Image courtesy of Dr Heydenrych.

Abbreviations: TC, temporal crest; Z-f, zygomatico-facial; SO, supraorbital; IO, infraorbital.

\section{Functional Vascular Anatomy (Angiosomes)}

The skin's three-dimensional functional angiosomes are supplied by a single source vessel and bordered by an anastomotic perimeter of either true or choke anastomoses. ${ }^{68}$ Whilst extravascular HA is well tolerated, intravascular placement induces severe vessel wall inflammation, predisposing to embolism. Pain may be a warning symptom even in the absence of cutaneous blanching but is not always present. Choke vessels respond with spasm to control or prevent flow across angiosome boundaries, impacting HA spread and necrosis of adjacent angiosomes.
Vascular complication sites fall within five specific choke angiosome territories of the facial, ophthalmic, maxillary, and superficial temporal arteries and may sometimes be remote from the primary injection site (Figures 14 and 15). ${ }^{69}$ These sites are the:

1. Glabella

2. Nasal bridge

3. Nasal tip

4. Central upper/lower lips

5. Nasolabial/cheek zone 


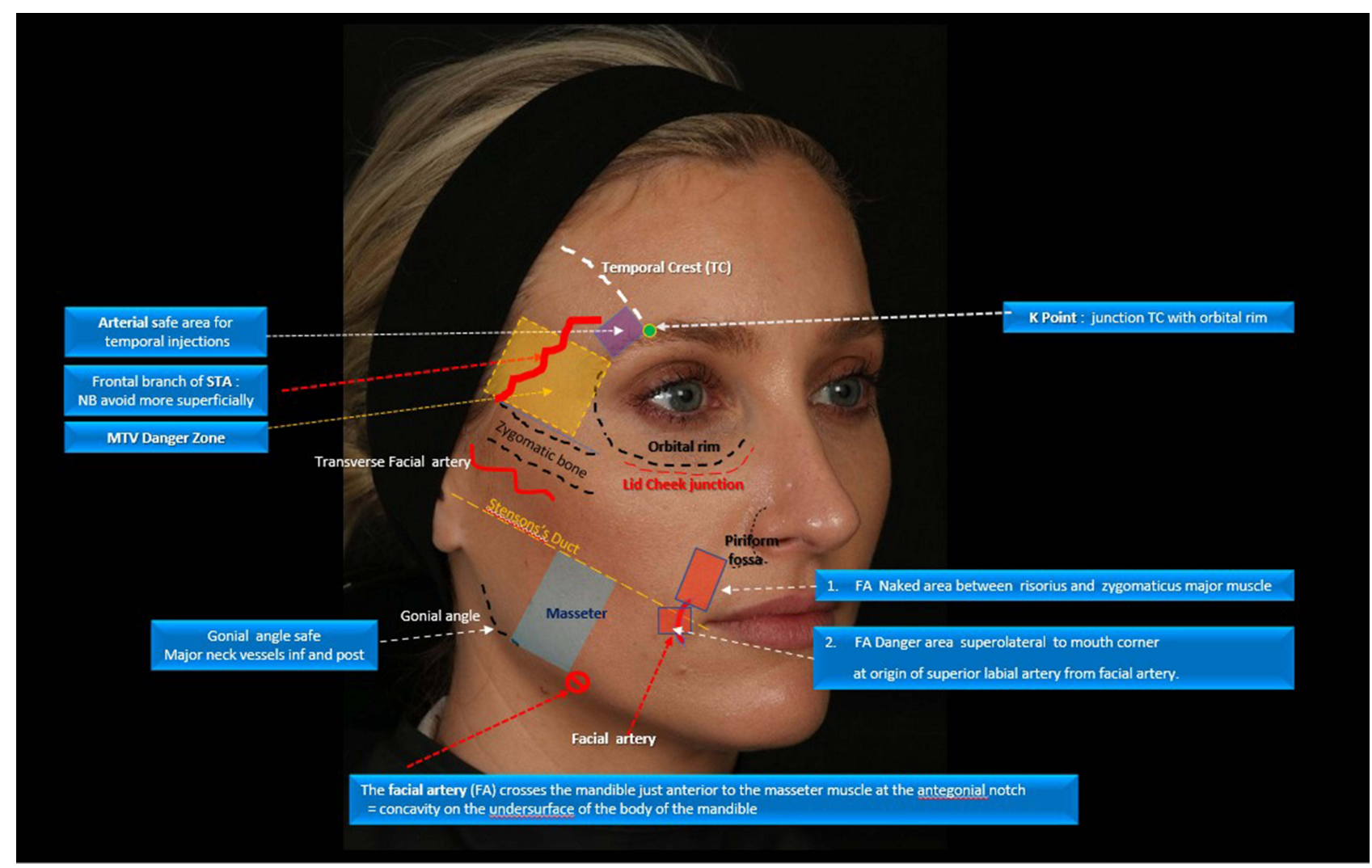

Figure II Oblique view illustrating topographical markings of bony landmarks and adjacent danger areas.

Note: Image courtesy of Dr Heydenrych.

Abbreviations: TC, temporal crest; MTV, middle temporal vein; FA, facial artery; STA, superior temporal artery .

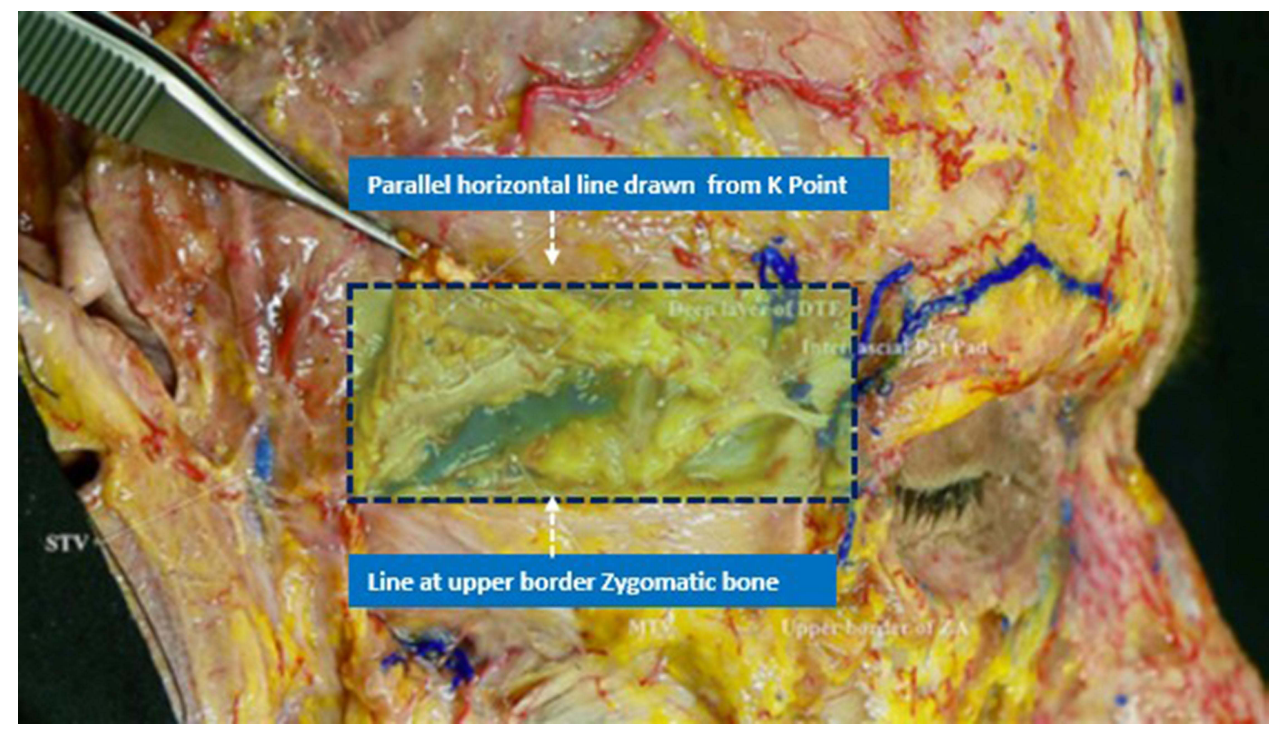

Figure 12 Temporal venous danger zone delineated by the upper margin of the zygomatic bone and a parallel horizontal line running from the $\mathrm{K}$ Point, at the junction of temporal crest (TC) and lateral orbital rim.

Scant upper facial and periorbital venous valves may cause arteriovenous shunting after choke vessel spasm, with resultant embolization to the ophthalmic vein, cavernous sinus, and brain.
True anastomoses, in contrast, link adjacent territories without caliber loss to potentially allow unimpeded embolic passage to remote or contralateral facial sites. ${ }^{69}$ Three common true anastomotic connections are: 
Table 9 Ten Topographical Tracings

\begin{tabular}{|c|c|c|c|}
\hline & Structure & Importance & Other \\
\hline I. & $\begin{array}{l}\text { Temporal crest } \\
\text { (TC) }\end{array}$ & $\begin{array}{l}\text { Separates forehead from temple } \\
\text { May palpate more easily at } \\
\text { KPoint }\end{array}$ & $\begin{array}{l}\text { Ant deep TA runs } 18 \mathrm{~mm} \text { from TC } \\
\text { STA (frontal br) runs more superficially; variable course }\end{array}$ \\
\hline 2. & K Point (KP) & At Junction $\mathrm{TC}+$ orbital rim & $\begin{array}{l}\text { Measure/mark } \\
\text { I.Ant deep TA - I8mm from TC } \\
\text { 2.Frontal branch STA (variable, more superficial, pull away) }\end{array}$ \\
\hline 3. & $\begin{array}{l}\text { Temporal fossa } \\
\text { injection } \\
\text { Marking of "safer } \\
\text { zone" }\end{array}$ & $\begin{array}{l}\text { I cm up and over (lateral) from } \\
\text { K Point } \\
\text { Sup-med, shallower aspect of } \\
\text { fossa }\end{array}$ & $\begin{array}{l}\text { Ant deep TA: runs } 18 \mathrm{~mm} \text { from TC } \\
\text { - STA frontal branch: at variable distance UNprotected by this marked zone in more } \\
\text { superficial plane } \\
\text { - NB identifies upfront }\end{array}$ \\
\hline 4. & $\begin{array}{l}\text { Zygoma Upper } \\
\text { border } \\
\text { Zygoma lower } \\
\text { border } \\
\text { Malar eminence }\end{array}$ & $\begin{array}{l}\text { Danger: } \\
\text { Do NOT angle needle or slide } \\
\text { above/below bone during } \\
\text { injection! }\end{array}$ & $\begin{array}{l}\text { - MTV danger zone in zone } 2 \mathrm{~cm} \text { above upper border } \\
\text { - Transverse FA runs } 1 \mathrm{~cm} \text { below inf zygomatic border } \\
\text { - From plumb line at lateral iris to ear } \\
\text { - At depth of } \mathrm{I}-1.2 \mathrm{~cm} \\
\text { - Zygomatico-facial foramen (single or multiple) } \\
\text { NB caution when injecting on bone }\end{array}$ \\
\hline 5. & $\begin{array}{l}\text { MTV venous } \\
\text { zone }\end{array}$ & $\begin{array}{l}\text { Lies between } 2 \text { parallel lines } \\
(\sim 2 \mathrm{~cm}) \\
\text { I. upper border zygoma } \\
\text { 2. 2. parallel line from KPoint }\end{array}$ & $\begin{array}{l}\text { - Zone extends } 2 \mathrm{~cm} \text { above upper border zygomatic arch } \\
\text { - Danger: NTPE, cavernous sinus embolism } \\
\text { - Sentinel vein drains into MTV }\end{array}$ \\
\hline 6. & $\begin{array}{l}\text { Mid-pupillary } \\
\text { line (MPL) }\end{array}$ & $\begin{array}{l}\text { Vertical line through mid-pupil } \\
\text { Pupils in straight gaze }\end{array}$ & $\begin{array}{l}\text { - 2nd vertical line, 3-4 mm medial to MPL (= plumb line at medial iris) transects the } \\
\text { SO, IO and mental foramens } \\
\text { - Mental artery exits foramen on bone } \\
\text { - Submental artery runs in superficial fat avoid by deep injection on bone }\end{array}$ \\
\hline 7. & $\begin{array}{l}\text { Orbital rim: } \\
\text { Lateral }+ \text { inferior } \\
\text { border } \\
\text { Supraorbital rim } \\
\text { (SOR) }\end{array}$ & $\begin{array}{l}\text { Fixed bony inferior orbital rim } \\
\text { NOT= lid-cheek junction (LCJ), } \\
\text { which descends with age }\end{array}$ & $\begin{array}{l}\text { - IO foramen lies } 6-8 \mathrm{~mm} \text { inferior to rim 3-4 mm medial to mid-pupillary line } \\
\text { - Single or multiple } 1 O \text { vessels exit at } 45 \text { degrees } \\
\text { - Approach from lateral (bony hood) } \\
\text { - Foramen/notch } 2.4 \mathrm{~cm} \text { from midline }-1.5 \mathrm{~cm} \text { above SOR: SO + ST arteries: pass } \\
\text { from deep - sup/on frontalis ophthalmic art branches (ICA) } \\
\text { NB Depth of skin - bone: } \sim 2-4 \mathrm{~mm}(\sim 2.4 \mathrm{~mm}) \\
\text { Vessel size } \sim 1.8 \mathrm{~mm}(=0.6 \mathrm{~mm} \text { of play!) }\end{array}$ \\
\hline 8 & $\begin{array}{l}\text { Masseter: ant } \\
\text { border }\end{array}$ & $\begin{array}{l}\text { FA crosses mandible } \mathrm{Icm} \text { ant to } \\
\text { border } \\
\text { On periosteum at antegonial } \\
\text { notch; palpable } \\
\text { Pulsation }\end{array}$ & Best identified whilst clenching \\
\hline 9. & $\begin{array}{l}\text { "Naked areas" } \\
\text { of Facial artery }\end{array}$ & $\begin{array}{l}\text { Exposed FA; no overlying } \\
\text { muscles } \\
2 \text { areas lateral to oral } \\
\text { commissure }\end{array}$ & $\begin{array}{l}\text { I. Between risorius and Zyg Maj } \\
\text { 2. Sup-lat angle mouth at origin of sup labial artery from FA }\end{array}$ \\
\hline \multirow[t]{2}{*}{10} & Gonial angle & Safe injection area on bone & Major neck vessels run post and inferior; avoid facial nerve ${ }^{94}$ \\
\hline & Piriform fossa & $\begin{array}{l}\text { Safer injection area on bone or } \\
\text { superficial. } \\
\text { Avoid the middle lamella }\end{array}$ & Stay on bone \\
\hline
\end{tabular}

Note: Data from Kumar et al. ${ }^{93}$

Abbreviations: TC, temporal crest; TA, temporal artery; STA, superficial temporal artery; br, branch; FA, facial artery; NTPE, non-thrombotic pulmonary embolism; SO, supraorbital; IO, infraorbital; MTV, middle temporal vein; IO, infraorbital; SO, supraorbital; ST, supratrochlear; SOR, supraorbital rim; LCJ, lid-cheek junction. 


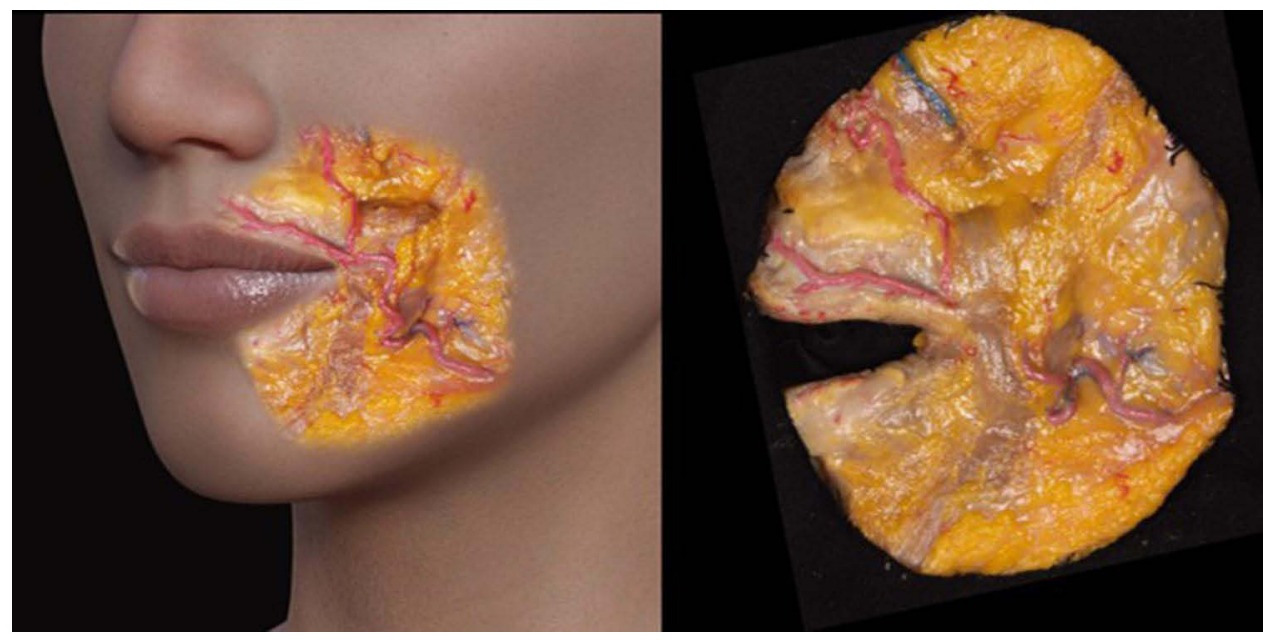

Figure I 3 Naked areas of facial artery.

Notes: Reproduced with permission from Pirayesh A, Bertossi D, Heydenrych I, editors. Aesthetic Facial Anatomy Essentials for Injections. Boca Raton: CRC Press; 2020.66 Copyright 2020 Taylor \& Francis.

1. Angular artery with dorsal nasal or supratrochlear artery

2. Across nasal tip

3. Across upper or lower lips

When injection pressure is lower than systemic arterial pressure, anterograde vascular occlusion causes downstream flow to vascular tributaries, resulting in predominantly skin surface changes. Displacement against arterial blood flow causes retrograde vascular occlusion, with emboli traversing back to a vascular bifurcation to cause anterograde occlusion in more posterior locations upon stabilization of arterial pressure, effecting more distal capillary non-perfusion. ${ }^{70}$

\section{Nitroglycerin Paste During Vascular Occlusion}

A recent overview advocates the adjuvant use of nitroglycerin in pending vascular occlusion. ${ }^{71}$ However, choke vessel spasm is deemed a major determinant for the location and extent of tissue necrosis and because nitroglycerin paste may induce choke vessel dilation to alleviate flowlimiting spasm, allowing expansion of the number of affected angiosomes and increasing the area of tissue necrosis, the use of nitroglycerin paste is discouraged. ${ }^{69}$

\section{The Use of Diagnostic Ultrasound}

Although technically intricate, accurately performed and interpreted ultrasound may offer a valuable risk reduction tool during blinded injection procedures (Figures 16 and 17). ${ }^{59}$

Uses include:

1. Upfront vessel localization for prevention of intravascular injection: ${ }^{54}$

2. Localization and treatment of acute vascular occlusion:

The amount, location, and depth of injected HA fillers may be identified, enabling targeted delivery of hyaluronidase.

Table 10 Differences Between "Gentle Pinch" and “Deep Pinch” with Non-Dominant Hand During Temporal Injection

\begin{tabular}{|l|l|l|}
\hline & Gentle Pinch & Deep Pinch \\
\hline Tissue layers involved & $\begin{array}{l}\text { Bunches up the skin and subcutaneous fat with minimal } \\
\text { movement of STF }\end{array}$ & $\begin{array}{l}\text { Separates skin, subcutaneous fat and STF layers from } \\
\text { superficial layer of DTF }\end{array}$ \\
\hline Vascular relation & $\begin{array}{l}\text { STA runs in superficial part of STF, just deep to the pinched } \\
\text { tissue }\end{array}$ & $\begin{array}{l}\text { Avascular loose areolar tissue plane lies deeper to the } \\
\text { pinched tissue, STA being pulled up in the pinched tissue }\end{array}$ \\
\hline Injection advice & $\begin{array}{l}\text { Plane under this pinch is used as the most superficial plane for } \\
\text { fillers in temple, after marking and staying away from the STA }\end{array}$ & $\begin{array}{l}\text { Can be used as the middle plane for filler injection in the } \\
\text { temple taking care of temporal branch of the facial nerve }\end{array}$ \\
\hline
\end{tabular}




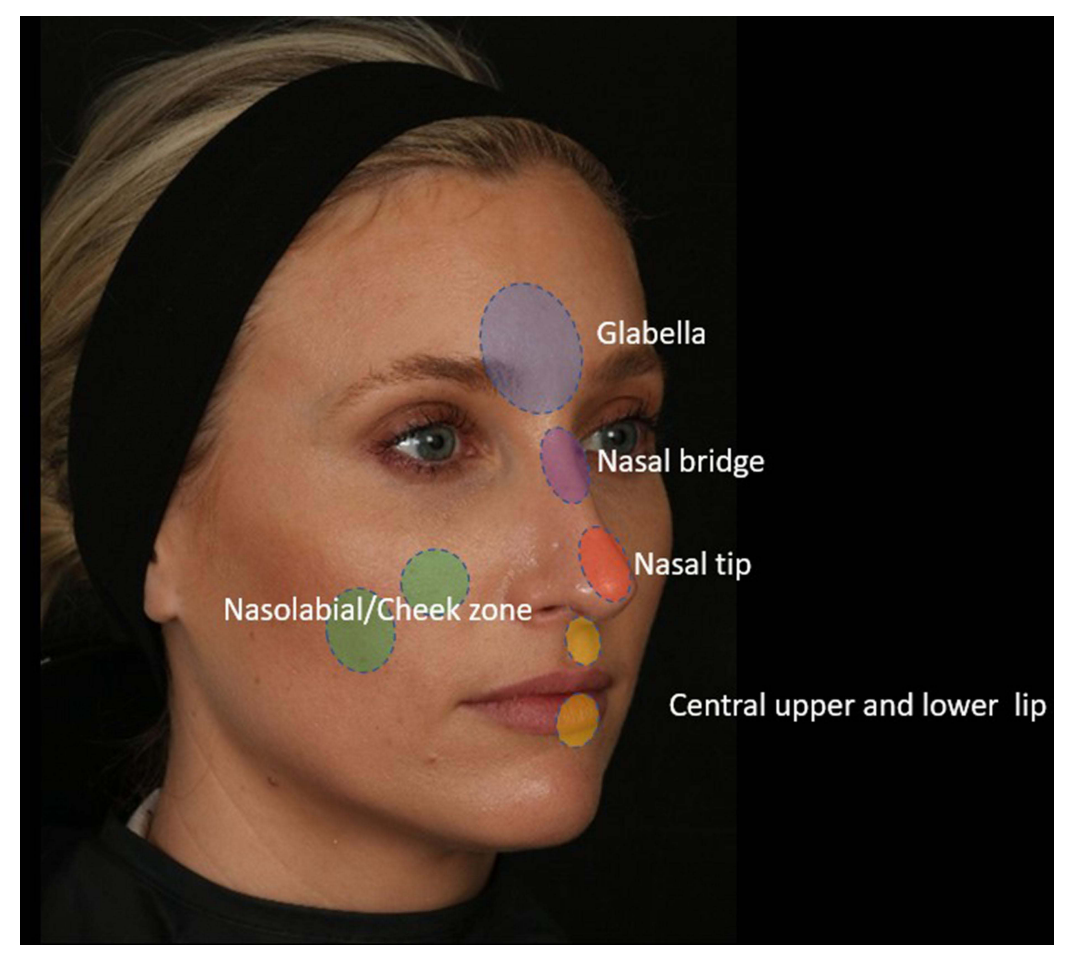

Figure 14 Diagram illustrating the most frequently affected choke anastomotic HA embolic sites.

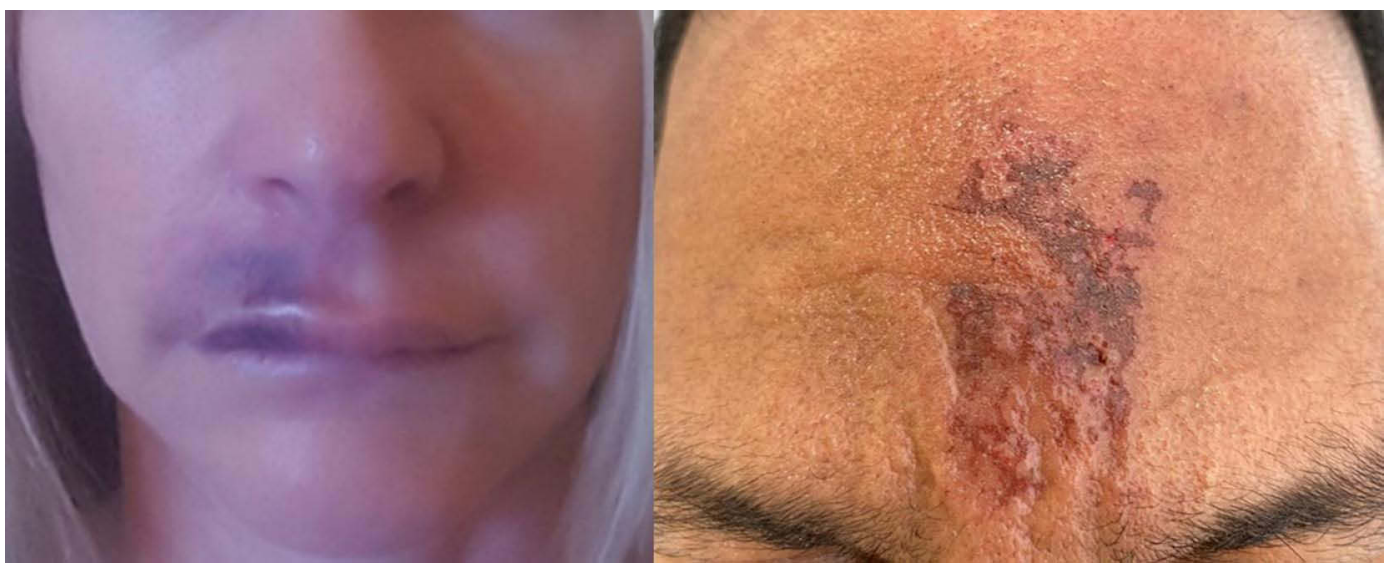

Figure I5 Vascular occlusion illustrating choke anastomotic distributions. Note: Images courtesy of Dr K De Boulle.

3. Product identification during late-onset events. ${ }^{59}$

It is advisable to align with an expert referral center in this regard.

\section{Technical Knowledge}

Unlimited online access to procedural techniques may blur the boundaries between possibilities and capabilities. It is important to grasp that acquiring motor hand skills involves both cognitive spatio-temporal and motoric learning components. Especially during initial learning phases, cognitive representation accrues more rapidly than muscle-specific representations which develop only after extensive practice.${ }^{72}$ Attempting injection procedures after online instruction only thus carries inherent risks. Considering the potentially grave sequelae of incorrect placement through minute variations in needle positioning, angulation and plunger control, it has never been more relevant to develop methods for gauging inherent hand skills. Needle skills training forms an integral component of the author's teaching practice and is useful in refining differential dexterity for controlling factors such as 

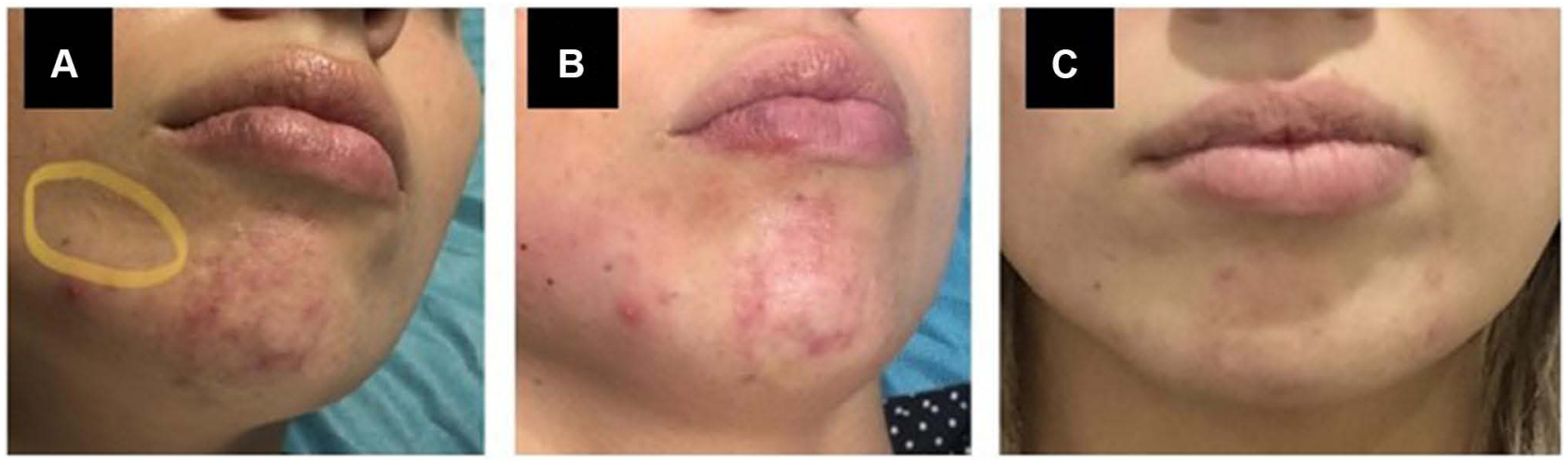

Figure 16 Vascular obstruction: $60 \mathrm{IU}$ hyaluronidase under ultrasound guidance (A) pre-Rx (B) 2h post -Rx (C) I-week post- Rx. Yellow circle denotes injection area. Note: Images courtesy of Dr Stefania Roberts.

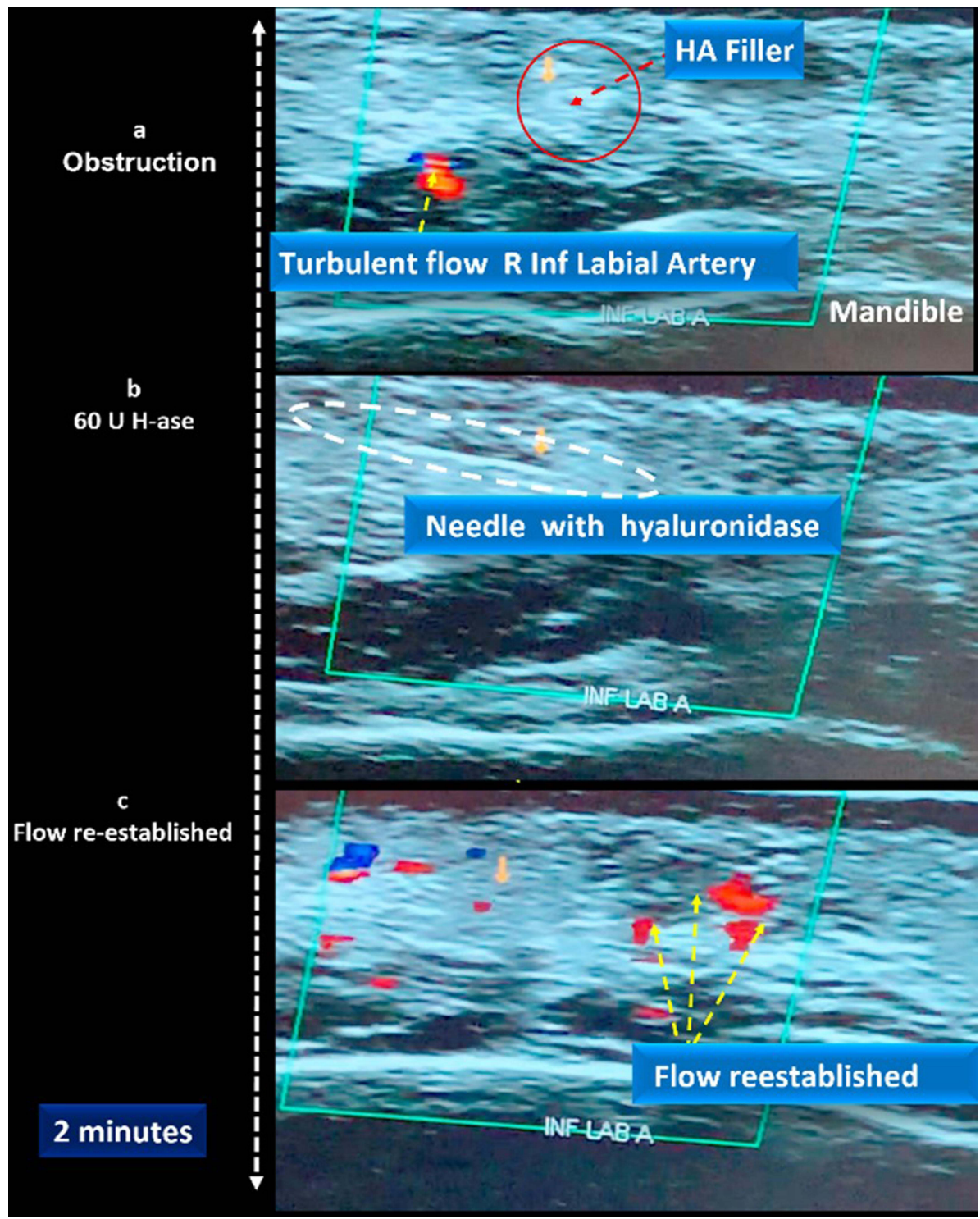

Figure 17 Ultrasound-guided Hyaluronidase treatment illustrating resolution of obstruction over 2 minutes (60 IU) Hyaluronidase. Note: Ultrasound images courtesy of $\mathrm{Dr}$ Stefania Roberts.

Abbreviations: $\mathrm{HA}$, hyaluronic acid; $\mathrm{R}$ inf, right inferior; $\mathrm{H}$-ase, hyaluronidase; $\mathrm{U}$, international units. 
needle position, angle, volume and injection speed (Figure 18).

\section{Volume and Speed}

Dexterous hand control, slow injection speed, and constant vigilance for undue pain which may portend intravascular placement are vital. Watershed perfusion areas such as the glabella or nasal tip should be constantly observed for fleeting blanching, mandating immediate cessation of injection. Blindness has been reported with volumes as low as $0.2 \mathrm{~mL}$ of HA filler, whilst $0.085 \mathrm{~mL}$ may fill the supratrochlear artery from skin to orbit. ${ }^{73}$ Large boluses carry a higher risk for biofilm, with recommendation being for bolus size of less than $0.2-0.3 \mathrm{~mL}$.

\section{The Aspiration Controversy}

Although the real-time clinical utility of pre-injection aspiration is controversial, ${ }^{74-80}$ all injectors are ultimately aligned in avoidance of intravascular incidents. No single method guarantees safety, despite individual preference for

A

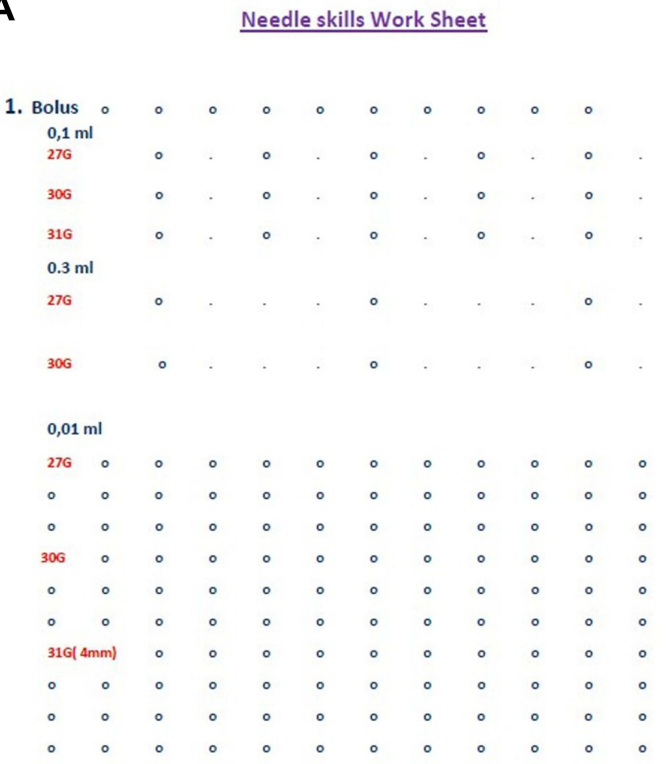

2. Microbolus (31G) aspiration or constant needle movement, thus the following should be borne in mind.

1. Negative aspiration does not guarantee safe injection - slow, careful, low-volume injection is mandatory.

2. Adequate aspiration time should be allowed (5-7 seconds).

3. Waiting times for visualizing flashback may be affected by physiochemical and rheological properties, with some products requiring longer negative pressure.

4. Not all injectors are equally able to maintain a steady needle position on bone.

5. Awareness of bevel angle (eg, 45 degrees vs perpendicular) in relation to tissue plane and vascularity is vital.

6. With the needle in perpendicular position, the bevel tip still may be in a dangerous vascular plane despite a stable needle tip on bone as in the forehead or temple (aSTA).

7. Intravascular placement is possible with a cannula, especially with $<25 \mathrm{G}$, and in the presence of underlying fibrosis or skin tethering.

B

3.tinear
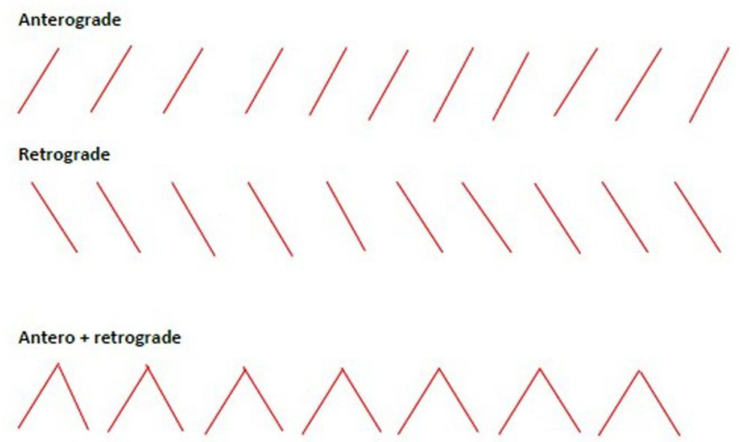

4. Fanning

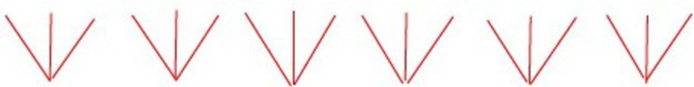

5. Aspiration and tip stabilisation

6.Angle of needle

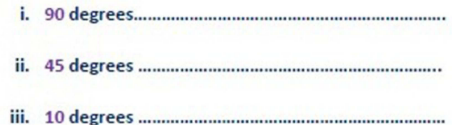

Figure 18 Needle Skills Worksheet. A laminated copy is used for regular extrusion practice utilizing sonar gel/expired products. Proprioceptive memory regarding volume control, needle resistance, and positional angulation may be refined. (A) Refining of volume control (B) refinement of needle course stability and angle. 
8. Insightful knowledge of vascular anatomy is mandatory, especially pertaining to "z-axis" or vessel depth.

9. Constant vigilance of watershed areas such as nasal tip and glabella is mandatory as these areas often demonstrate early, fleeting blanching.

10. Pain is not invariably present with intravascular injection.

Injection Angles vs Placement Depth (Needle/Cannula) Angulation dictates injection depth and safety, mandating constant awareness (Figure 19, Table 11).

\section{Algorithms and Checklists}

A thorough pre- and post-procedural history, with careful clinical examination, should elucidate predisposing factors and facilitate categorization of adverse events. After accurate diagnosis, the majority of problems may be managed through algorithms for:

1. Allergic hypersensitivity reactions

2. Vascular events
3. Edema
4. Late-onset adverse events (LOAEs)

Early occurring symptoms and algorithms include factors as illustrated in Figures 20 and 21:

Late occurring adverse events may be classified according to symptoms as non-inflammatory, inflammatory or edema, and treated according to algorithms as shown in Figure 22. Anatomical factors, such as decreased muscle tonus of the orbicularis oculi, can cause symptoms such as the shelving illustrated in Figure 23. Edema may have a variable clinical presentation as demonstrated in Figure 24 and be classified according to temporal onset as seen in Figure 25. Post-procedural swelling (Figure 26) should be clinically differentiated from type 1 hypersensitivity reactions (Figure 27). Importantly, sterile abscesses may occur either as early or late-onset events, mandating targeted antibiotic therapy with incision and drainage in order to avoid tissue necrosis (Figure 28). The differential diagnosis of skin discoloration after fillers is varied (Figure 29). It is critically important to recognize the mottled or livedoid pattern of

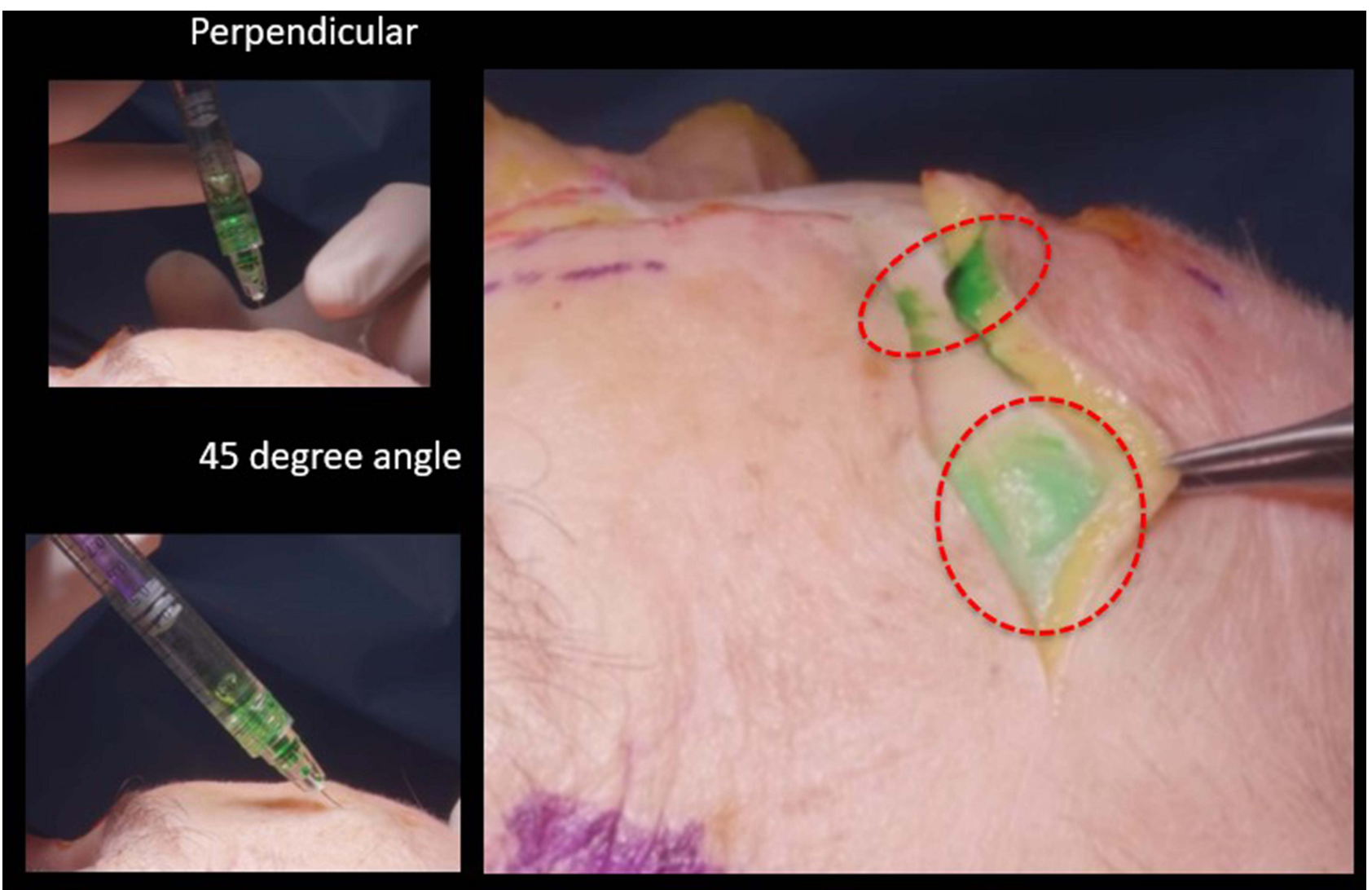

Figure 19 For upper forehead injections, the avascular subgaleal plane may be accessed with needle at 45 degrees to bone. Perpendicular injection may cause bevel height to extend to the vascular supragaleal plane. 
Table I I Angles vs Depth (Needle or Cannula)

\begin{tabular}{|l|l|l|}
\hline Angle & Placement (z-axis) & Functional Implication \\
\hline 10 degrees (needle) & Superficial intradermal & "Superficial blanching technique" \\
\hline 45 degrees (needle) & $\begin{array}{l}\text { On bone, bevel down in: } \\
\text { Upper forehead } \\
\text { Temporal }\end{array}$ & $\begin{array}{l}\text { Avoids supragaleal/vascular bevel position } \\
\text { Avoids bevel in aSTA plane (pinch/pull away) }\end{array}$ \\
\hline 90 degrees & $\begin{array}{l}\text { To bone: } \\
\text { - Midface }\end{array}$ & $\begin{array}{l}\text { Above: } \\
\text { - Midface levators }\end{array}$ \\
\hline 45 degrees, cannula & $\begin{array}{l}\text { DAO } \\
\text { Below: }\end{array}$ & $\begin{array}{l}\text { May: } \\
\text { Suppress action/lengthen upper lip } \\
\text { Improve gummy smile } \\
\text { Suppress action/improve downturn of mouth }\end{array}$ \\
\hline & Midface levators & $\begin{array}{l}\text { May: } \\
\text { Strengthen levator action } \\
\text { Worsen gummy smile }\end{array}$ \\
\hline
\end{tabular}

Abbreviations: STA, superficial temporal artery; DAO, depressor anguli oris.

early vascular occlusion and not to confuse subsequent pus-

tulation with herpes simplex infection.
Post-Treatment Checklist

Patient adherence to the factors as noted in Table 12 should be encouraged.

\section{Hypersensitivity}

Pre-Treatment Checklist

Country-specific Covid guidelines should be Aesthetic practices should be geared for efficient manageadhered to. ${ }^{81}$ ment of hypersensitivity events, albeit rare (Table 13). ${ }^{82}$

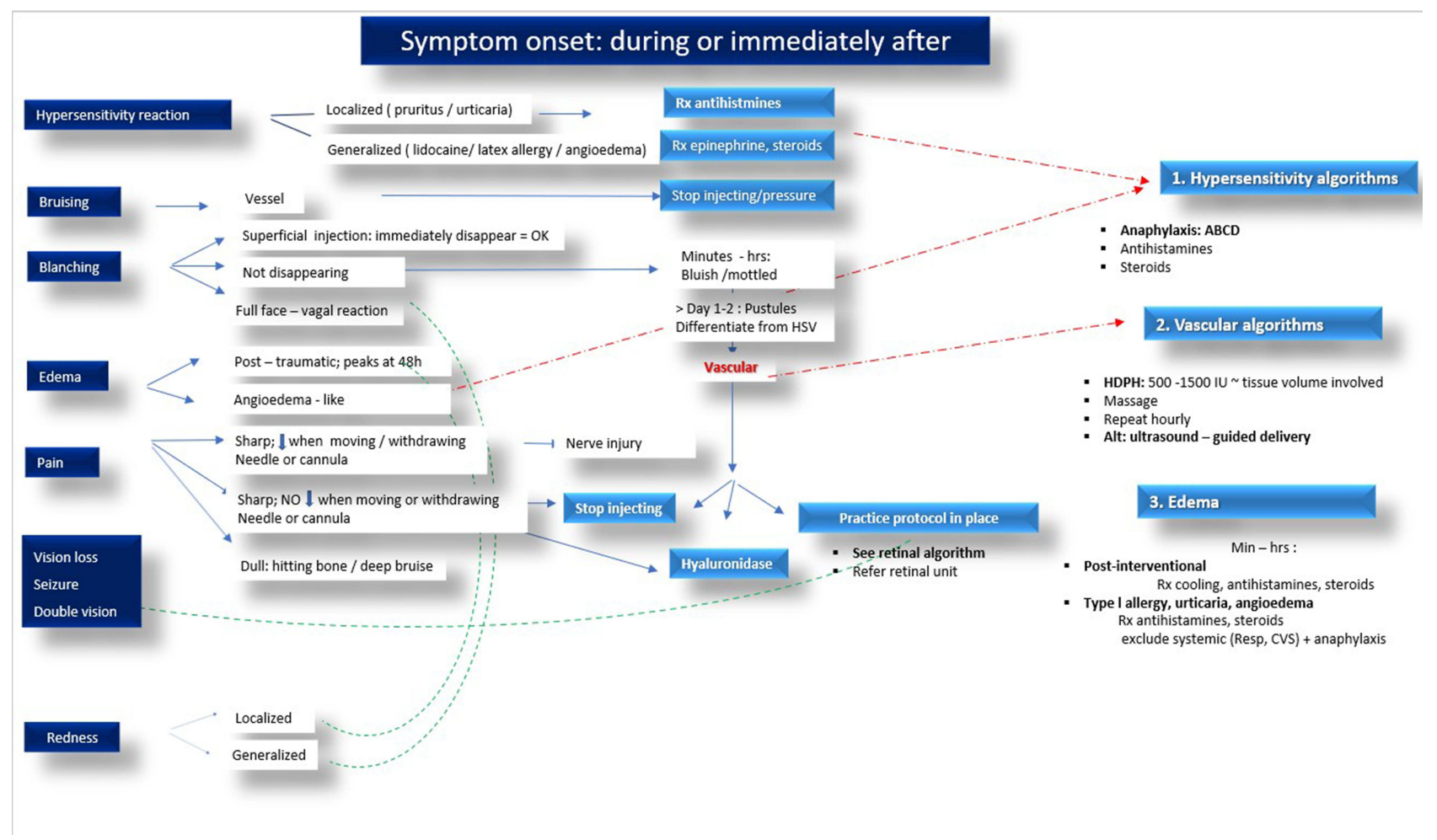

Figure 20 Early occurring symptoms. 


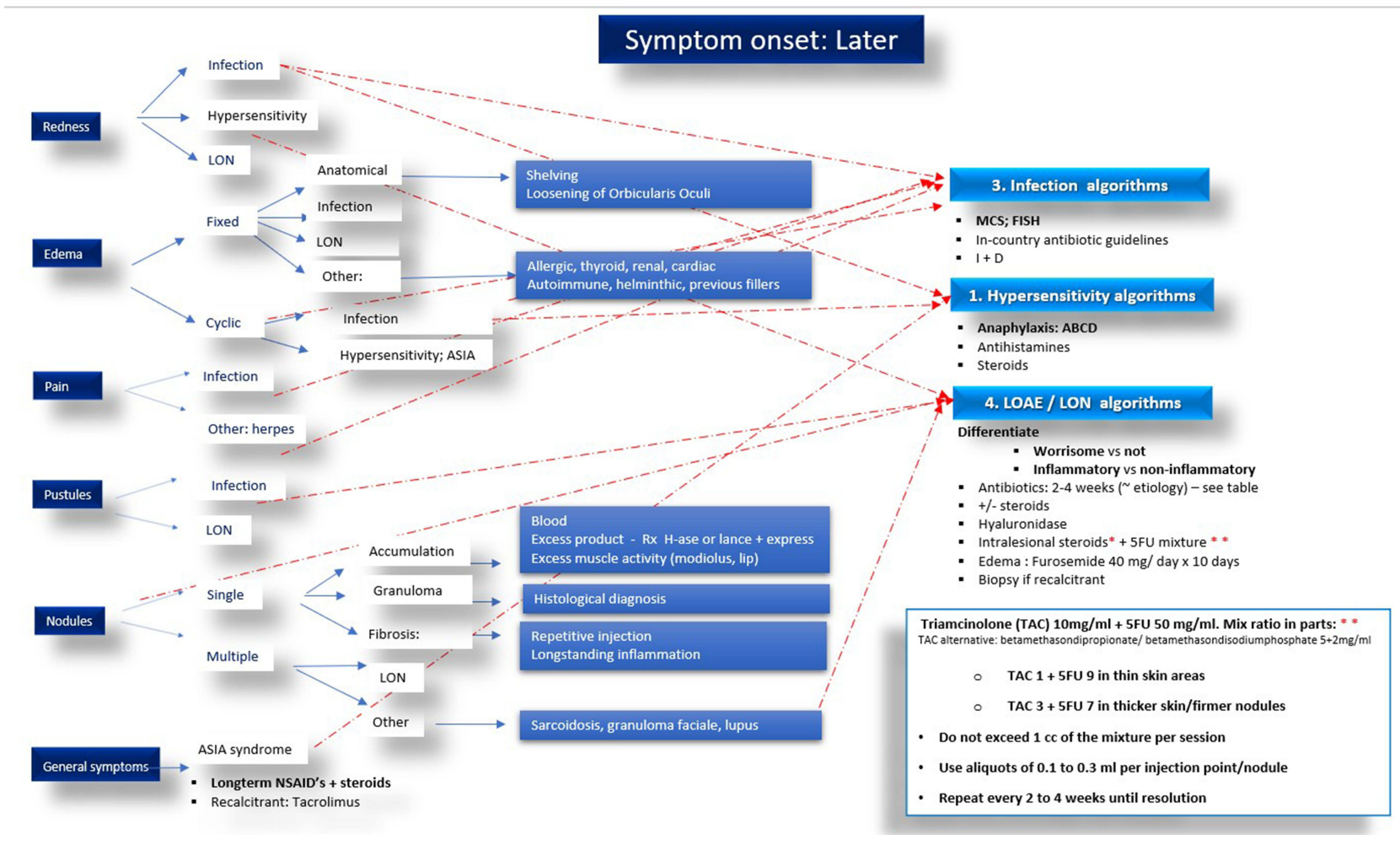

Figure 2 I Late-occurring symptoms of LOAEs.

Abbreviations: HDPH, high-dose pulse hyaluronidase; Resp, respiratory system; CVS, cardiovascular system.

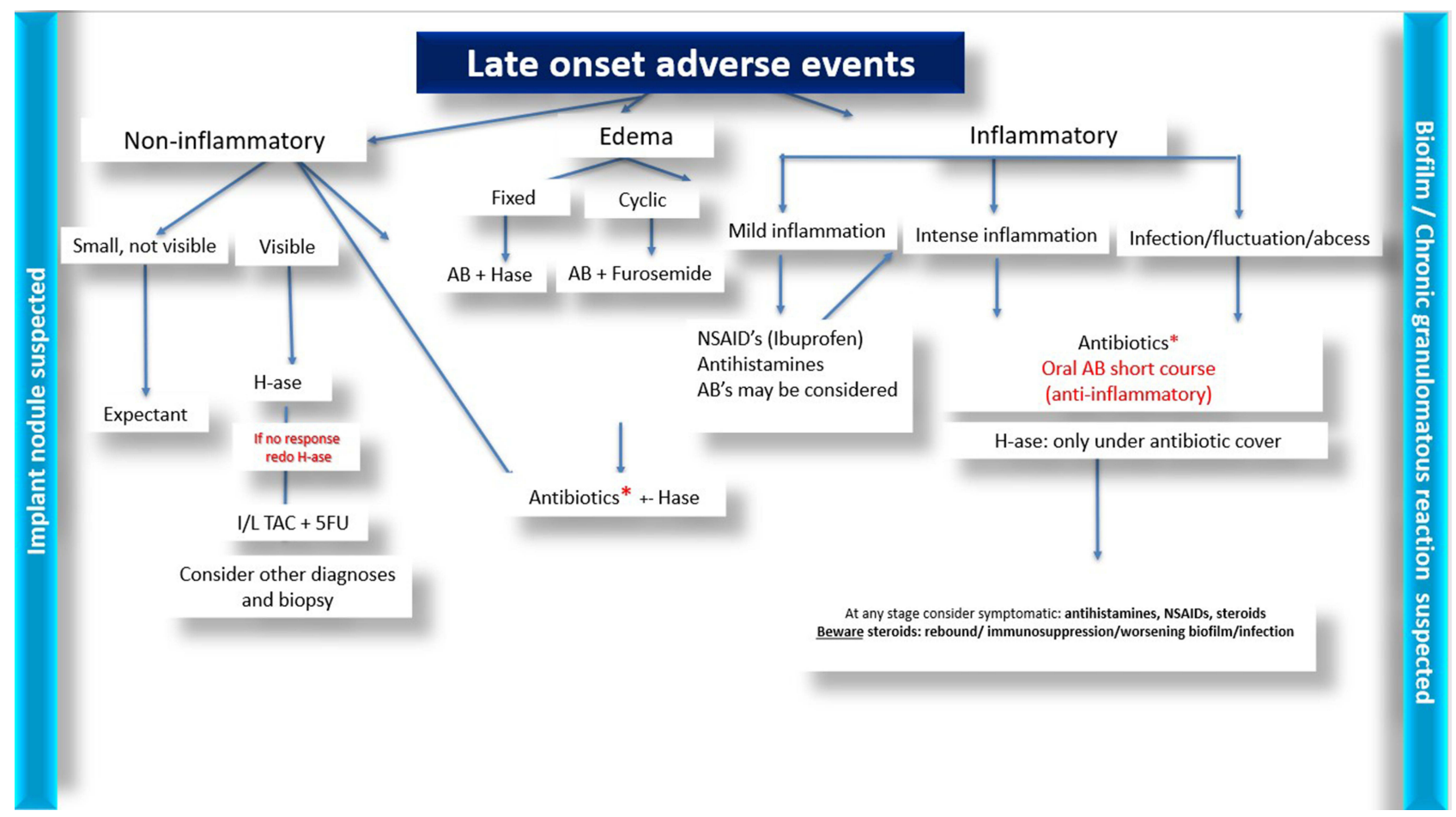

Figure 22 Classification of LOAEs. 


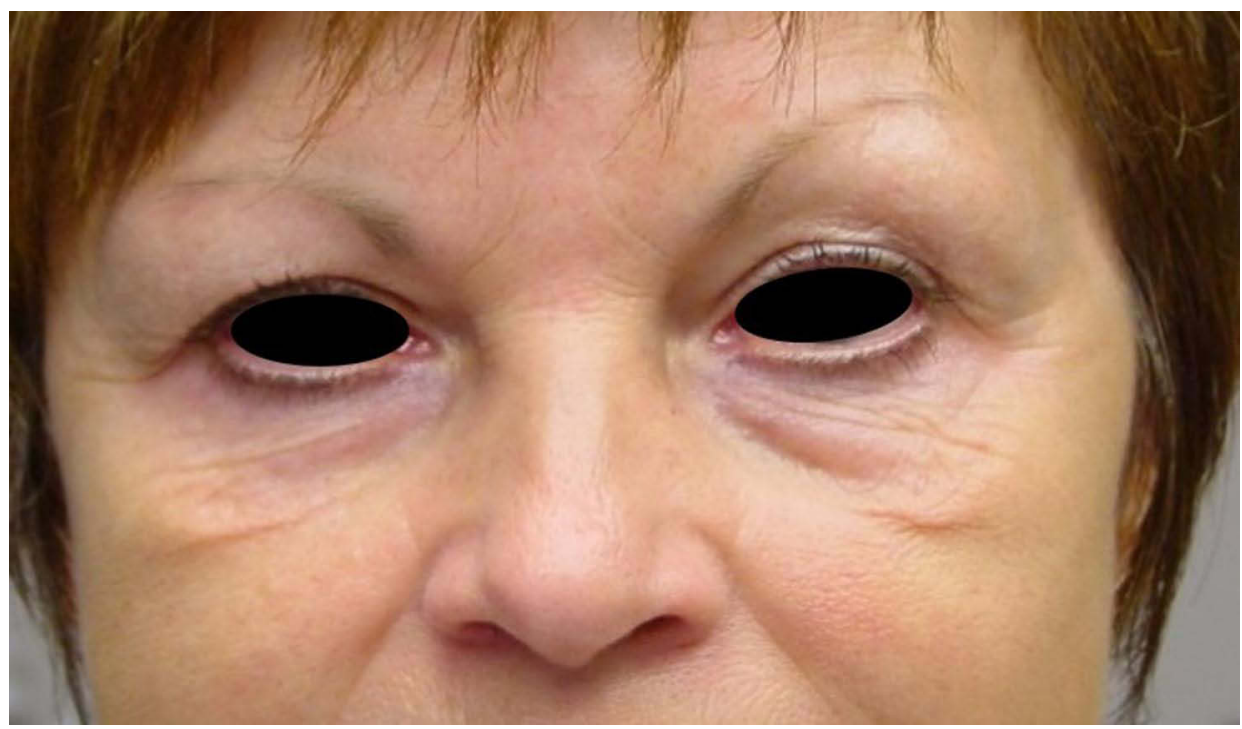

Figure 23 Patient demonstrating shelving Rx: surgery.

Note: Image courtesy of Dr De Boulle.

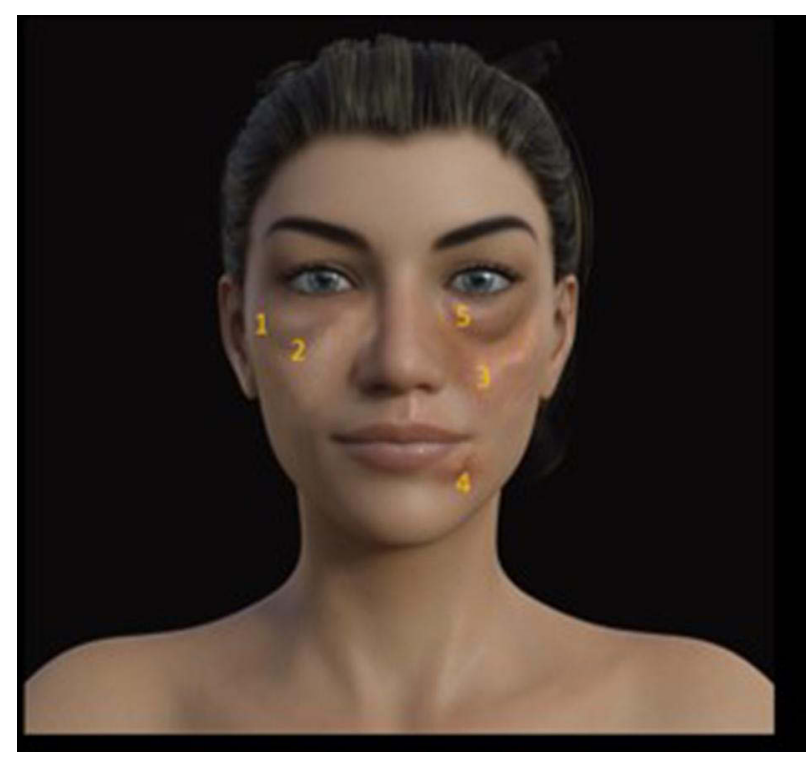

Figure 24 Differential diagnosis of swelling. I = edema; 2 = malar edema; 3 = late inflammatory response syndrome; $4=$ late onset nodules (LON); 5 = persistent intermittent delayed swelling.

Notes: Adapted with permission from Pirayesh A, Bertossi D, Heydenrych I, editors. Aesthetic Facial Anatomy Essentials for Injections. Boca Raton: CRC Press; 2020. ${ }^{66}$ Copyright 2020 Taylor \& Francis.

Computer reminders are suggested for emergency drug expiry dates.

\section{Vascular Events}

Sufficient hyaluronidase should be available for the management of intravascular events, with high-dose pulse hyaluronidase (HDPH) currently deemed the gold standard (see Table 14). Dosage is according to tissue volume or areas involved. At least $5 \times 1500$ IU (or equivalent dosage in other format vials) should be available in-clinic. Check expiry dates.

Hyaluronidase treatment for intravascular placement should be instituted as soon as possible, with cut-off time regarded as 4 days. Later treatment options include antiinflammatory medications, antibiotics, hyperbaric oxygen, and standard wound care. 


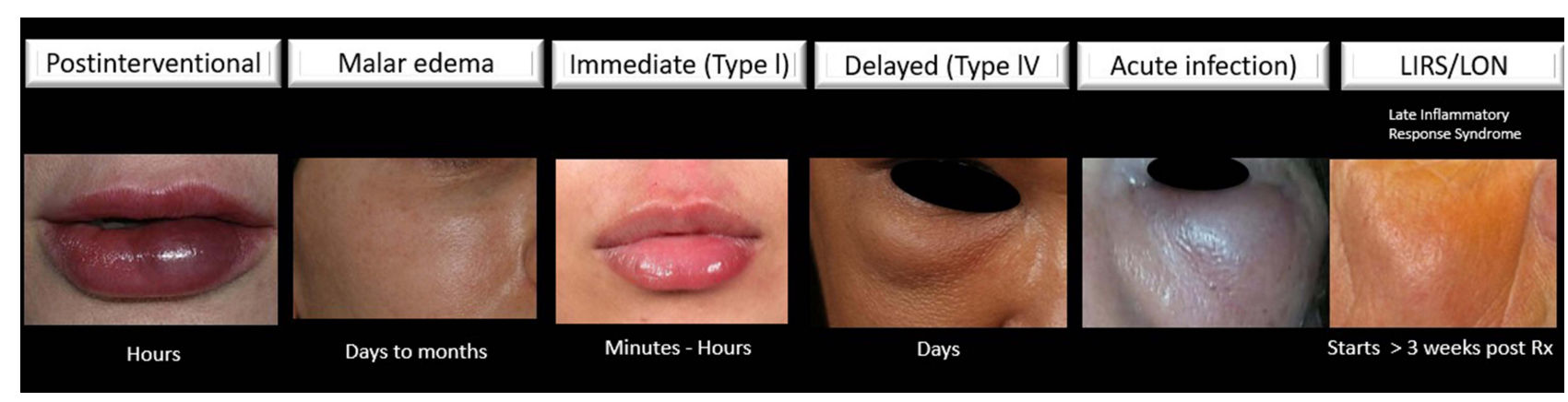

Figure 25 Temporal onset of post-procedural swelling.

Notes: Reproduced with permission from Pirayesh A, Bertossi D, Heydenrych I, editors. Aesthetic Facial Anatomy Essentials for Injections. Boca Raton: CRC Press; 2020. ${ }^{66}$ Copyright 2020 Taylor \& Francis.

Abbreviations: LIRS, late inflammatory response syndrome; LON, late-onset nodules.

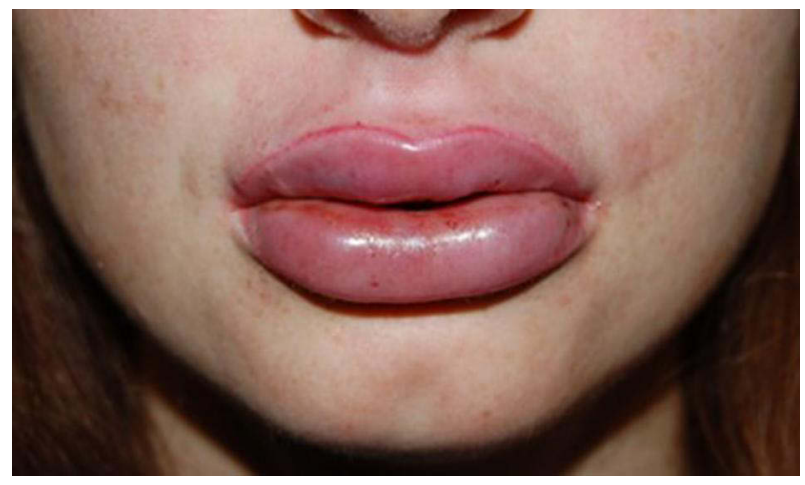

Figure 26 Patient demonstrating postprocedural swelling.

Note: Image courtesy of Dr De Boulle.

Abbreviations: LIRS, late inflammatory response syndrome; LON, late-onset nodules.

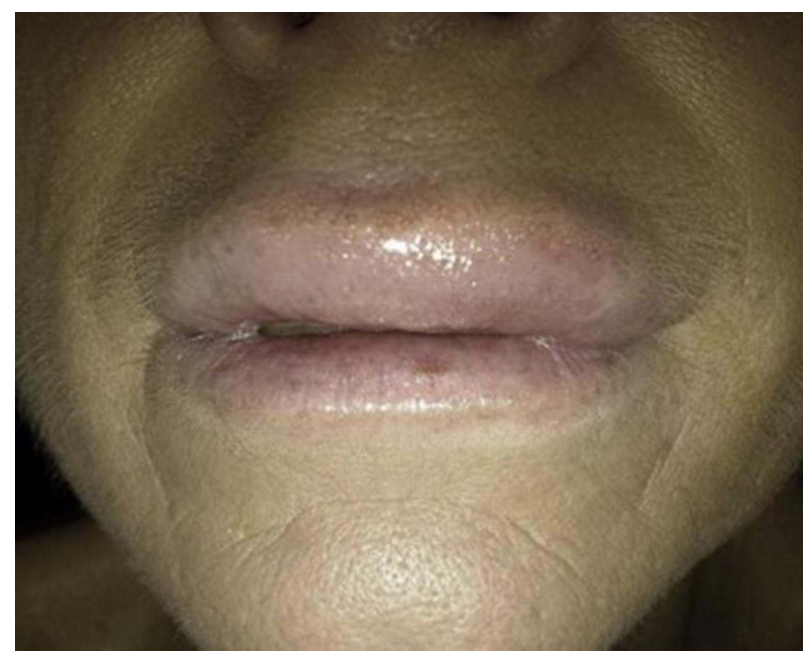

Figure 27 Patient demonstrating Type I hypersensitivity.

Note: Image courtesy ofDr De Boulle. 

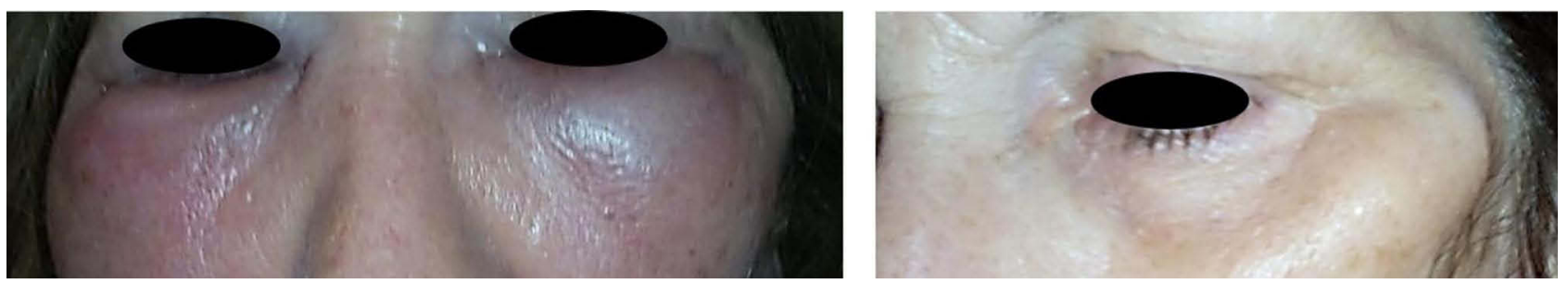

Figure 28 Evolution of a sterile abscess during the first-week post -filler. Rx: targeted antibiotic therapy, with incision and drainage, is vital to prevent tissue necrosis. This presentation may also occur as a late-onset event.

Note: Image courtesy of Dr Heydenrych.

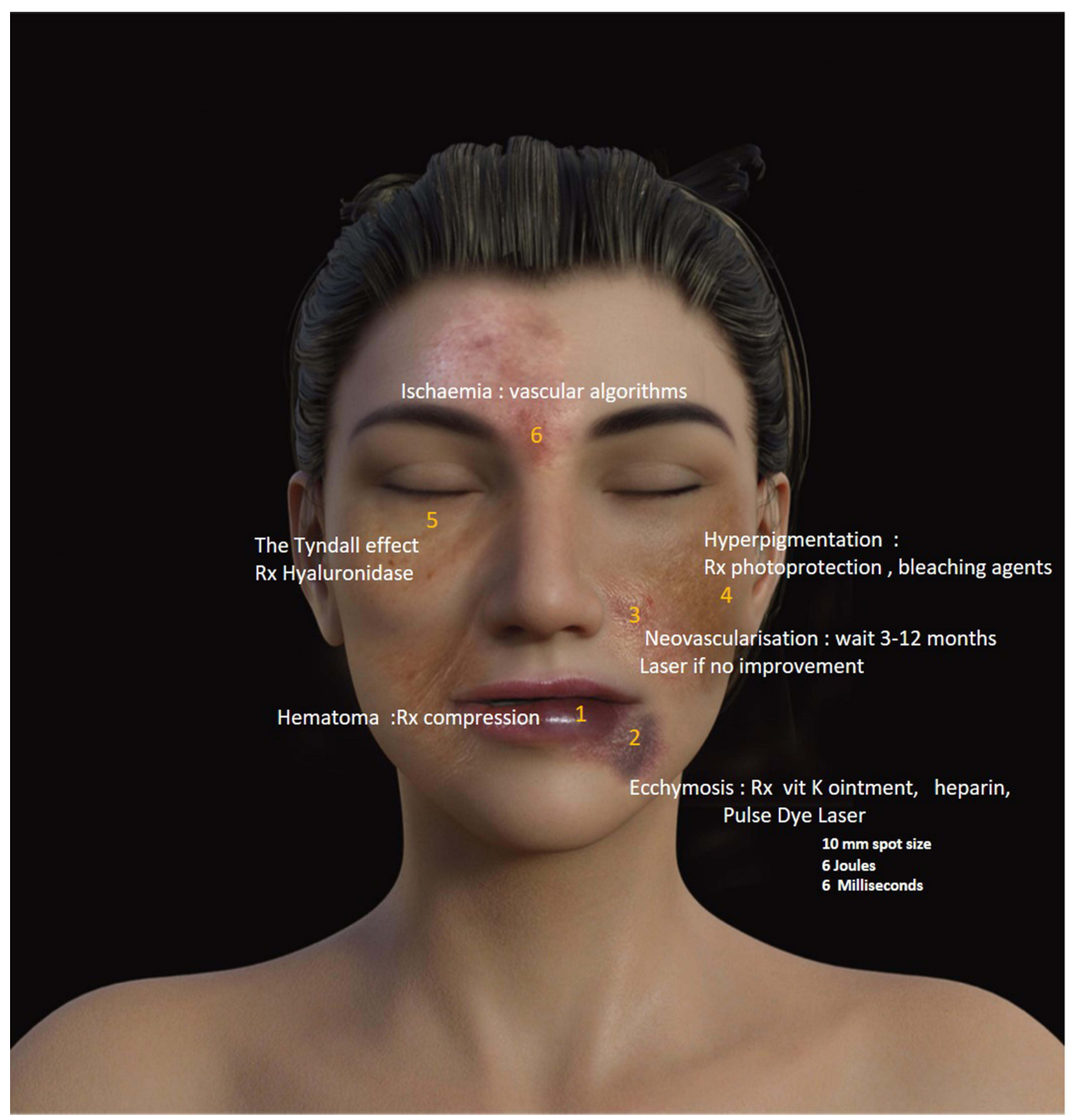

Figure 29 Differential diagnosis of skin discoloration: I. Hematoma; 2. Ecchymosis; 3. Neovascularization; 4. Hyperpigmentation; 5. The Tyndall effect; 6. Ischaemia. Notes: Adapted with permission from Pirayesh A, Bertossi D, Heydenrych I, editors. Aesthetic Facial Anatomy Essentials for Injections. Boca Raton: CRC Press; 2020. ${ }^{66}$ Copyright 2020 Taylor \& Francis.

\section{Visual Complications}

There is a paucity of local management guidelines for visual complications after dermal fillers. A recent study cited widespread unawareness of existing protocols despite awareness of the complication in $75 \%$ of respondents, underscoring the urgent need for multidisciplinary collaboration and structured protocols. ${ }^{83}$

In contrast to previous studies, a recent systematic review detailing HA fillers only showed no cases after lower face treatment, with 32/44 events occurring after 
Table 12 Suggested Inclusions for Post-Procedure Checklist

\begin{tabular}{|c|c|}
\hline $\begin{array}{l}\text { Practice contact } \\
\text { number ( } 24 \mathrm{~h})\end{array}$ & \\
\hline Please report & $\begin{array}{l}\text { Color change/pain/undue swelling } \\
\text { Blistering } \\
\text { Anything else that is concerning you } \\
\text { Please note that procedural swelling peaks at } \\
48 \text { hrs }\end{array}$ \\
\hline $\begin{array}{l}\text { Suggested skin } \\
\text { products for next } 24 \mathrm{~h}\end{array}$ & 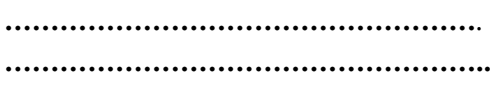 \\
\hline Please avoid & $\begin{array}{l}\text { Contaminated make-up } \\
\text { Unclean tap water } \\
\text { Undue touching/fiddling } \\
\text { Dental procedures/oral hygienist for } 2-4 \\
\text { weeks } \\
\text { Vaccination: time window } 2-4 \text { weeks } \\
\text { Recent paper suggested } 4 \text { to } 8 \text { weeks } \\
\text { between vaccination and filler, but overall } \\
\text { incidence of LOAEs in correlation with } \\
\text { infection/vaccination at this time not known }\end{array}$ \\
\hline $\begin{array}{l}\text { Discuss other planned } \\
\text { procedures/EBD's }\end{array}$ & \\
\hline Your follow-up date is & $\ldots / \ldots / \ldots$ \\
\hline Time & $\ldots h . \ldots$ \\
\hline
\end{tabular}

Abbreviation: EBD, energy-based device.

Table 13 Management of Anaphylaxis with Emergency Crash Cart

\begin{tabular}{|l|l|}
\hline Airway & Mouthpiece, Laryngoscope, tube \\
\hline Breathing & Ambubag \\
\hline Circulation & $\begin{array}{l}\text { IV butterfly, infusion set } \\
\text { Saline/Ringers/Plasma expanders }\end{array}$ \\
\hline Drugs & $\begin{array}{l}\text { Adrenalin I: I000 } \\
\text { HI + H2 Antihistamines } \\
\text { iv steroids } \\
\text { Vasopressors } \\
\text { Chewable aspirin }\end{array}$ \\
\hline $\begin{array}{l}\text { Ophthalmic } \\
\text { event }\end{array}$ & $\begin{array}{l}\text { Rebreathing: Brown paper bag timolol, } \\
\text { apraclonidine, bimatoprost drops } \\
\text { Vision: Snellen App } \\
\text { Pupillary reflexes: Light source }\end{array}$ \\
\hline
\end{tabular}

Abbreviation: IV, intravenous.
Table 14 High-Dose Pulse Hyaluronidase (HDPH) for Intravascular Events.

\begin{tabular}{|l|l|l|}
\hline \multicolumn{2}{|l|}{ High Dose Pulse Hyaluronidase (HDPH) } \\
\hline Dosage & $\begin{array}{l}\text { Standard dosage } \\
\text { Lip, nose, and forehead } \\
2 \text { areas } \\
3 \text { areas }\end{array}$ & $\begin{array}{l}500 \text { IU per area } \\
\text { Act as multipliers } \\
1000 \text { IU per hour } \\
1500 \text { IU per area }\end{array}$ \\
\hline Protocol & - Inject at least every 60-90 minutes until skin color has normalized \\
and capillary refill time has improved \\
- Massage to increase tissue contact with hyaluronidase \\
- Aim to complete treatment within 72 hours of onset for complete \\
resolution \\
- Keep patient in-clinic for observation and treatment until the capil- \\
lary refill has improved
\end{tabular}

Note: Data from Delorenzi. ${ }^{95}$

Abbreviation: IU, international units.

injection of the glabella and nose. ${ }^{84}$ Blindness has been reported with volumes as low as $0.2 \mathrm{~mL}$ of HA filler, whilst $0.085 \mathrm{~mL}$ may fill the supratrochlear artery from skin to orbit. $^{73}$

Visual loss is often instantaneous and may be painless. Early, accurate documentation of visual signs is mandatory for subsequent decisions in the retinal referral centre (Table 15).

\section{Treatment}

There is currently a lack of indisputable evidence for reversal of injection-related visual compromise (IRVC), with conflicting reports regarding the merits of retrobulbar, supraorbital, and supratrochlear hyaluronidase and an urgent need for multidisciplinary collaboration. ${ }^{85}$

Many studies are flawed by incomplete documentation. It is imperative that vision is documented upfront in order to establish prognosis.

\section{Neurologic Assessment}

Given the $24 \%$ incidence of concomitant cerebral involvement, the exact mechanism of which still needs elucidation, a multi-speciality approach including neurological and neurosurgical examination is vital. 
Table 15 Prognosis

\begin{tabular}{|l|l|}
\hline Glabellar injections & Often CRAO, with sudden painless loss of vision; Snellen acuity of only counting fingers \\
\hline Nasal injections & Often OAO; 6 prognostic types, diffuse occlusion carrying worse prognosis \\
\hline CRAO & $\begin{array}{l}\text { Poor prognosis; I5\% spontaneous recovery or after traditional rescue methods } \\
\text { Partial recovery has been documented I5 hrs after incomplete CRAO }\end{array}$ \\
\hline OAO & Poor prognosis \\
\hline BRAO & Better prognosis; quadrantal visual field with early preservation of central visual acuity \\
\hline Irreversible damage & $60-90$ minutes; may be less \\
\hline
\end{tabular}

Abbreviations: CRAO, central retinal artery obstruction; OAO, ophthalmic artery occlusion; BRAO, branch retinal artery occlusion.

Table 16 A Suggested Practice Protocol for Managing Ophthalmic Incidents in the Aesthetic Practice

\begin{tabular}{|c|c|c|}
\hline Retinal ER & $\begin{array}{l}\text { Contact person } \\
\text { Mobile number } \\
\text { Address }\end{array}$ & $\begin{array}{l}\text { Document time } \ldots \ldots \ldots \ldots \\
\ldots \ldots \ldots \ldots \ldots \ldots \ldots \ldots \ldots \\
\ldots \ldots \ldots \ldots \ldots \ldots \ldots \ldots \ldots\end{array}$ \\
\hline Practice & $\begin{array}{l}\text { Reporting staff member } \\
\text { Injecting physician }\end{array}$ & … \\
\hline $\begin{array}{l}\text { Stop injecting! } \\
\text { Product }\end{array}$ & $\begin{array}{l}\text { Staff: Call Retinal ER } \\
\text { What injected } \\
\text { Where (area) } \\
\text { How much } \\
\text { When }\end{array}$ & 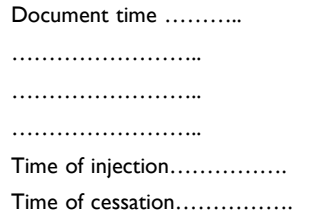 \\
\hline $\begin{array}{l}\text { Patient complaint } \\
\text { Symptom }\end{array}$ & $\begin{array}{l}\text { Vision reduced } \\
\text { Pain/Diplopia/Skin } \\
\text { Other symptoms }\end{array}$ & $\begin{array}{l}\mathrm{R} / \mathrm{L} \ldots \ldots \ldots \ldots \ldots \ldots \\
\mathrm{R} / \mathrm{L} \ldots \ldots \ldots \ldots \ldots \ldots \\
\ldots \ldots \ldots \ldots \ldots \ldots \ldots \ldots\end{array}$ \\
\hline Test eyes separately & (Occlude opposite eye) & \\
\hline \multicolumn{3}{|l|}{ Test vision + Document } \\
\hline & $\begin{array}{l}\text { Light perception } \\
\text { Hand movement } \\
\text { Finger count } \\
\text { Snellen chart (app) } \\
\text { Available reading material }\end{array}$ & 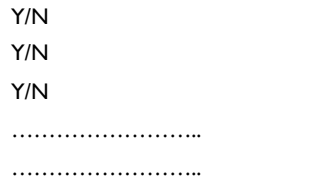 \\
\hline Pupillary reflex & R eye: $Y / N$ & L eye: $Y / N$ \\
\hline Medical RX decompress & $\begin{array}{l}\text { Aproclonidine drops } \\
\text { Timolol } 0.5 \% \text { drops } \\
\text { *Bimatoprost drops } \\
\text { Acetazolamide } 500 \mathrm{mg} \\
\text { Acetylsalicylic acid } \\
\text { *Nitroglycerin } 0,6 \mathrm{mg}\end{array}$ & $\begin{array}{l}\text { Every } 15 \text { minutes } \\
\text { Oral } \\
\text { Sublingual }\end{array}$ \\
\hline Ocular massage & Supine, eyes closed & $\begin{array}{l}\text { Firm pressure } \\
5-15 \mathrm{sec}, \text { release } \\
\text { Repeat cycle } 5 x\end{array}$ \\
\hline Rebreathing (vasodilatory) & Brown paper bag & 10 minutes per 30 minute cycles \\
\hline Hyaluronidase (dissolve) & $>1000-1500 \mathrm{IU}$ & $\begin{array}{l}\text { - } \\
\text { - }\end{array}$ \\
\hline Emergency transfer & & $\begin{array}{l}\text { - } \text { *Retrobulbar Hase } \\
\text { - Retinal specialist }\end{array}$ \\
\hline
\end{tabular}

Note: *Conflicting evidence.

Abbreviations: RB, retrobulbar; PG, peribulbar; ST, supratrochlear artery; SO, supraorbital artery. 


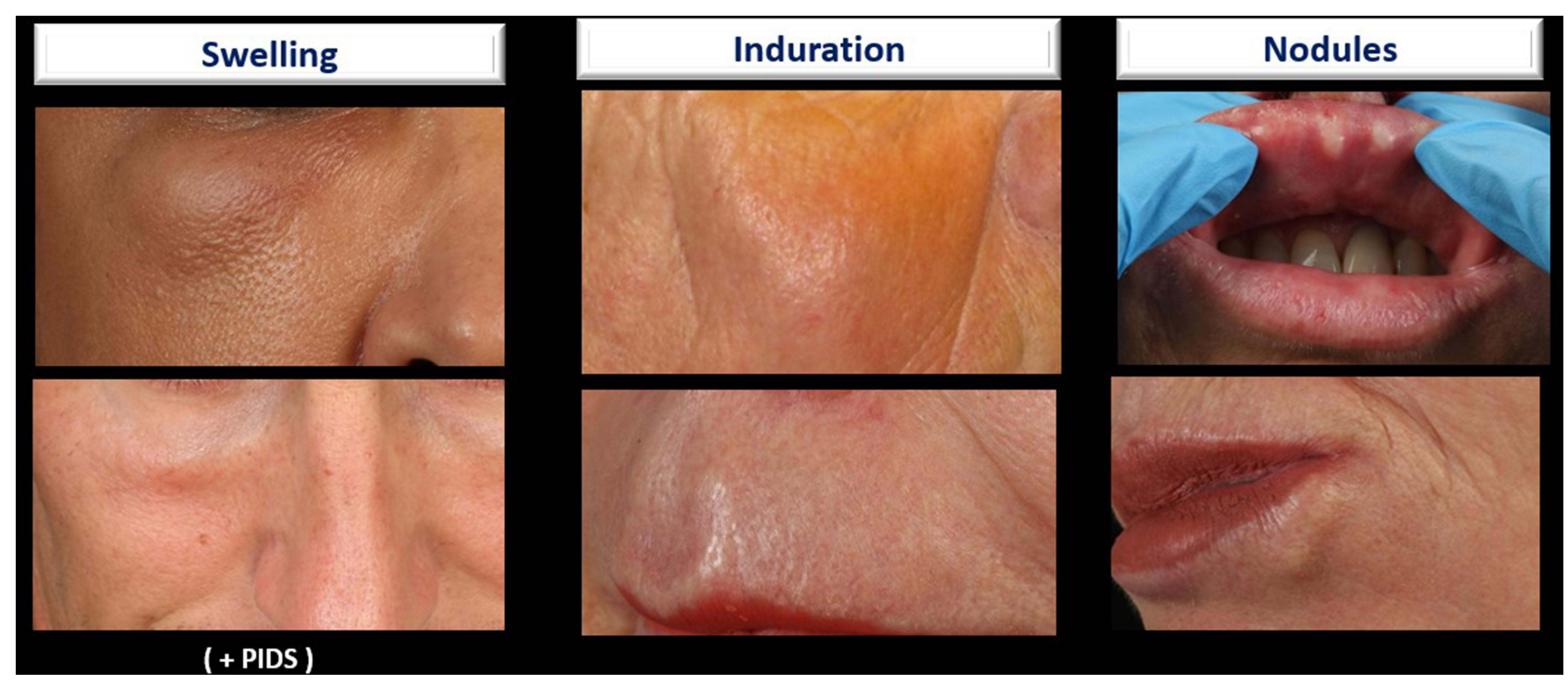

Figure 30 The clinical spectrum of LOAEs includes inflammatory or non-inflammatory manifestations, including swelling, induration, and nodules. Onset is usually after $>4$ weeks.

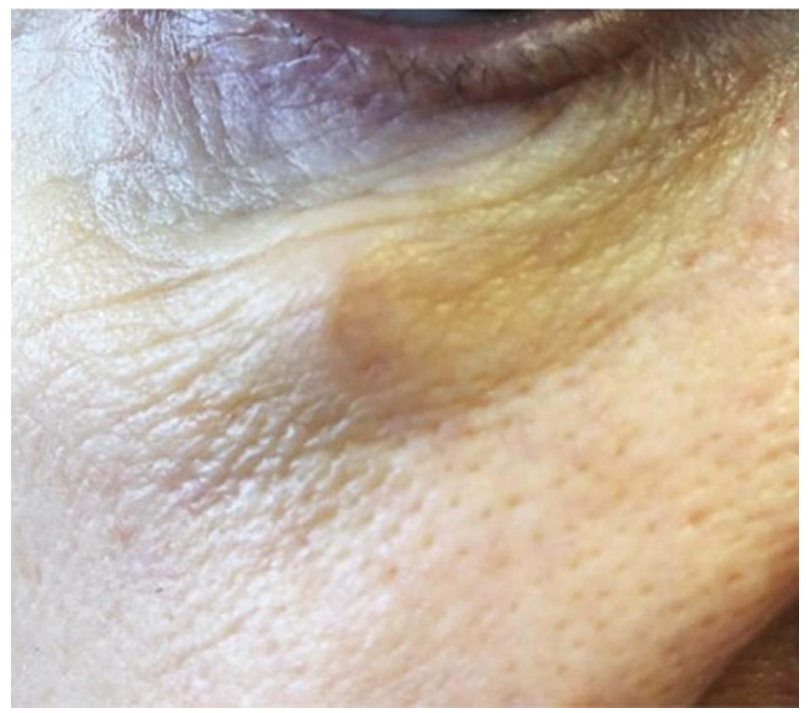

Figure 3 I Patient with LOAE (nodule). Despite lack of improvement on long-term antibiotics, total resolution was affected with colchicine.

Practice Protocol for Injection-Related Visual Compromise (IRVC)

Although no universal protocol exists, factors as noted in Table 16 should be considered and documented. Upfront medico-legal advice may be advisable.

\section{Late-Onset Adverse Events}

LOAEs may present clinically as swelling, induration, nodules, or intermittent swelling (persistent intermittent delayed swelling $=$ PIDS) (Figures 30-32).
The ASIA Syndrome (Autoimmune/Inflammatory Syndrome Induced by Adjuvants)

In genetically predisposed hosts such as HLA B8 or HLA DRB1*- positive individuals, biomaterials may trigger delayed immune responses, eventually progressing to granulomatous or autoimmune disorders falling into the ASIA diagnostic complex (Table 17). ${ }^{31}$ Two or more stimuli increase the risk of abnormal immune responses and include:

- Local trauma 


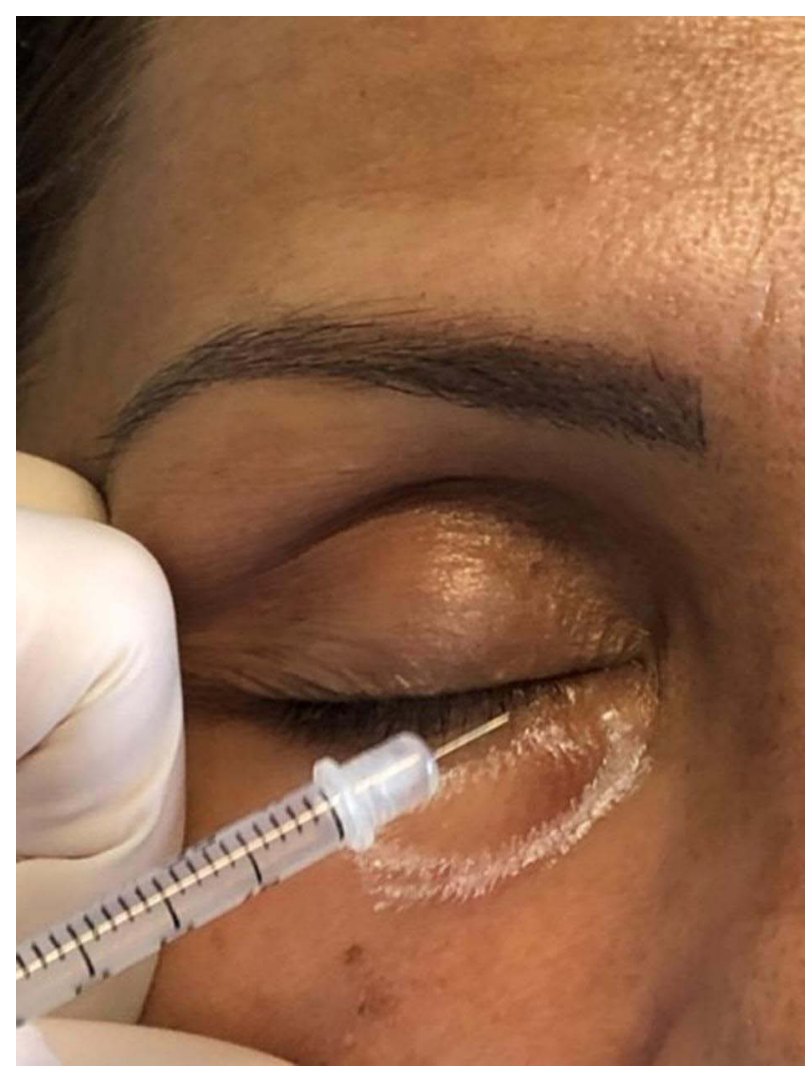

Figure 32 Patient with PIDS successfully treated with $0.1 \mathrm{~mL}$ of hyaluronidase. Note: Image courtesy of Dr A De Almeida.

- Infections

- Filler injections

- Vaccines

- Dental amalgams

- Menstrual exacerbations

HA is thought to trigger the immune system via adjuvant effect rather than primary antigenic immune response, being cited as potential trigger in 340/350 patients with previous filler treatments where filler removal effected improvement in $60 \%$ of cases. The adjuvant effect of microbial molecules may determine a limited autoimmune response vs evolution to fullblown disease.

\section{Infection}

Ciprofloxacin now carries an FDA black box warning and should not be prescribed for longer than 60 days (British National Formulary). Potential quinolone sideeffects, including colitis and prolonged QT interval, merit recommendation as third-line agents in case of intolerance, allergy, or contraindication to macrolides and tetracyclines. Dual antibiotic therapy should continue for four weeks, followed by patient re-assessment (Table 18). ${ }^{86}$

\section{Conclusion}

Facial filler treatment is a constantly evolving field mandating continuous reassessment and improvement. New challenges (eg, the COVID 19 SARS 2 pandemic) prompt new insights, with resultant evolution in the understanding, prevention, diagnosis and therapeutic approaches to filler complications.

The updated 10-point plan aims to empower aesthetic physicians to perform optimally through prudent patient selection, knowledgeable product choice, and attentive procedural planning. The most dreaded adverse events are vascular complications and filler-induced blindness. However, with a systematic approach, indepth knowledge of facial anatomy, and appropriate algorithms, the majority of adverse events are avoidable or manageable.

This updated version of our former publication attempts to illuminate salient background knowledge, whilst still embodying a practical reference guide to the cosmetic health-care practitioner. Hopefully, an increased understanding of safety factors may serve to protect not only our patients but also the future of aesthetic medicine. 
Table 17 ASIA Syndrome: Summary

\begin{tabular}{|c|c|}
\hline Onset & Usually $3 / 12$ post-filler; most $>12$ months \\
\hline Hypersensitivity & Type IV; sometimes I/III \\
\hline Mechanisms & $\begin{array}{l}\text { Heightened innate immunity, TLR binding, reinforced activity of antigen-presenting cells (APC's), raised local reactions to } \\
\text { antigens, and release of inflammatory cytokines }\end{array}$ \\
\hline $\begin{array}{l}\text { Clinical } \\
\text { presentation }\end{array}$ & $\begin{array}{l}\text { Gradual regional evolution, eventual systemic extension, or primary systemic autoimmune disease. Regional or widespread } \\
\text { localized inflammatory reactions, with rapid progression to all previously injected areas, should raise the possibility of the ASIA } \\
\text { syndrome }\end{array}$ \\
\hline Symptoms & $\begin{array}{l}\text { - As in autoimmune disease } \\
\text { - Commonly include arthralgia, general weakness, myalgia, palmar-digital erythema, and arthritis. } \\
\text { - Menstrual exacerbation, sometimes severe, has been ascribed to estrogens and TNF- } \alpha \text {, directly or through their influence on } \\
\text { vascular endothelial growth factor (VEGF). }{ }^{31,96}\end{array}$ \\
\hline Laboratory & Positive laboratory results include ANA $(80 \%+)$, hyper $\gamma$ globulinemia, raised ACE and LDH, positive anti-Ro and anti-TPO-AB. \\
\hline Treatment & $\begin{array}{l}\text { Challenging, generally requiring a combination of steroids and antibiotics. }{ }^{31} \\
\text { Long-term steroids, NSAIDs, Hydroxychloroquine, allopurinol, and high dose cetirizine have been utilized either alone or in } \\
\text { combination with good results and no adverse effects. }\end{array}$ \\
\hline Prognosis & $\begin{array}{l}\text { - In the absence of well-defined autoimmune disease, good clinical response in more than } 70 \% \text { after two years of chronic } \\
\text { treatment with strong combinations of anti-inflammatory and/or immunomodulating drugs. } \\
\text { - Practically, all refractory cases are sensitive to oral tacrolimus, usually at a low dose, which inhibits interleukin-2 (IL-2) } \\
\text { production and blocks T cell proliferation. }\end{array}$ \\
\hline
\end{tabular}

Note: Data from Alijotas-Reig, ${ }^{31}$ Clare and Rowley, ${ }^{63}$ and Mackern-Oberti et al. ${ }^{96}$

Table 18 Antibiotic Choice by Infection Origin (Adhere to Country-Specific Microbiotic Guidelines)

\begin{tabular}{|l|l|l|l|l|}
\hline Skin & Sinus & Dental & GIT & Low-Grade Infections \\
\hline Doxycycline & Doxycycline & Amoxicillin & Metronidazole & Doxycycline \\
Clindamycin & Cephalexin & Clindamycin & Clindamycin & Azithromycin \\
Clarithromycin & Amoxycillin + Clavulanic acid & Cephalosporin & Ciprofloxacin & \\
Azithromycin & & Amoxycillin + Clavulanic acid & & \\
\hline
\end{tabular}

\section{Consent}

Written informed consent for publication of their clinical details and/or clinical images was obtained from the patients. No ethical concerns were raised in this paper.

\section{Acknowledgment}

The authors would like to express deep gratitude to $\mathrm{PhD}$ candidate, Elizabeth Rademan, Centre for Research on Evaluation, Science and Technology (CREST), Stellenbosch University, South Africa, for the invaluable writing and editing assistance serving to significantly improve the manuscript.

\section{Disclosure}

Dr Izolda Heydenrych reports honoraria for advisory boards and lecturing from Allergan, outside the submitted work; and being a consultant for Allergan/AbbVie, LÓreal, LaRochePosay, SkinCeuticals, Genop Healthcare. Dr Koenraad De Boulle reports grants and personal fees from Allergan and Genévrier, outside the submitted work. The authors report no other potential conflicts of interest in this work.

\section{References}

1. Heydenrych I, Kapoor KM, De Boulle K, Goodman G, Swift A, Kumar N. A 10-point plan for avoiding hyaluronic acid dermal filler-related complications during facial aesthetic procedures and algorithms for management. Clin Cosmet Investig Dermatol. 2018;11:603-611. doi:10.2147/CCID.S180904

2. Gonzalez H, Hagerling C, Werb Z. Roles of the immune system in cancer: from tumor initiation to metastatic progression. Genes Dev. 2018;32(19-20):1267-1284. doi:10.1101/GAD.31461 7.118 
3. Brierley ME, Sansom-Daly UM, Baenziger J, McGill B, Wakefield CE. Impact of physical appearance changes reported by adolescent and young adult cancer survivors: a qualitative analysis. Eur $J$ Cancer Care (Engl). 2019;28(4):e13052. doi:10.1111/ecc.13052

4. Kang DH, Weaver MT, Park NJ, Smith B, McArdle T, Carpenter J. Significant impairment in immune recovery following cancer treatment Duck-Hee. Nurs Res. 2009;58(2):105-114. doi:10.1097/ NNR.0b013e31818fcecd.

5. Verma R, Foster RE, Horgan K, et al. Lymphocyte depletion and repopulation after chemotherapy for primary breast cancer. Breast Cancer Res. 2016;18(1):1-12. doi:10.1186/s13058-015-0669-x

6. Naidoo J, Page DB, Li BT, et al. Toxicities of the anti-PD-1 and antiPD-L1 immune checkpoint antibodies. Ann Oncol. 2015;26 (12):2375-2391. doi:10.1093/annonc/mdv383

7. Bisschop C, Bruijn MS, Stenekes MW, Diercks GFH, Hospers GAP. Foreign body reaction triggered by cytotoxic $\mathrm{T}$ lymphocyte-associated protein 4 blockade 25 years after dermal filler injection. $\mathrm{Br} \mathrm{J}$ Dermatol. 2016;175(6):1351-1353. doi:10.1111/bjd.14674

8. De Boulle K. A sting in the tail: filler nodules after monoclonal antibody treatment. Br J Dermatol. 2016;175(6):1149. doi:10.1111/bjd.15117

9. Pathmanathan S, Dzienis M. Cetuximab associated dermal filler reaction. BMJ Case Reports CP. 2019;12(8):e228882. doi:10.1136/ bcr-2018-228882

10. Hibler BP, Yan BY, Marchetti MA, Momtahen S, Busam KJ, Rossi AM. Facial swelling and foreign body granulomatous reaction to hyaluronic acid filler in the setting of tyrosine kinase inhibitor therapy. J Eur Acad Dermatol Venereol. 2018;32(6):e225. doi:10.1111/jdv.14749

11. Syunyaeva Z, Kahnert K, Kauffmann-Guerrero D, Huber RM, Tufman A. Dermal filler injections mimic tumor activity during immune checkpoint inhibition. Respiration. 2018;95(5):362-363. doi: $10.1159 / 000487601$

12. Dwivedi K, Prabhu IS, Bradley KM. Fluorodeoxyglucose activity associated with a cosmetic poly-L-lactide filler: a potential confounder on positron emission tomography and computed tomography. $\mathrm{Br} J$ Oral Maxillofac Surg. 2018;56(2):148-150. doi:10.1016/j.bjoms.2017.09.011

13. Carvalho HDA, Villar RC. Radiotherapy and immune response: the systemic effects of a local treatment. Clinics. 2018;73(1):1-11. doi:10.6061/clinics/2018/e557s

14. Lyle DB, Breger JC, Baeva LF, et al. Low molecular weight hyaluronic acid effects on murine macrophage nitric oxide production. $J$ Biomed Mater Res Part A. 2010;94(3):893-904.

15. Scheibner KA, Lutz MA, Boodoo S, Fenton MJ, Powell JD, Horton MR. Hyaluronan fragments act as an endogenous danger signal by engaging TLR2. J Immunol. 2006;177(2):1272-1281. doi:10.4049/ jimmunol.177.2.1272

16. Inchingolo F, Tatullo M, Abenavoli FM, et al. A hypothetical correlation between hyaluronic acid gel and development of cutaneous metaplastic synovial cyst. Head Face Med. 2010;6(1):13. doi:10.1186/1746-160X-6-13

17. Creadore A, Watchmaker J, Maymone MBC, Pappas L, Vashi NA, Lam C. Cosmetic treatment in patients with autoimmune connective tissue diseases: best practices for patients with lupus erythematosus. $J \mathrm{Am}$ Acad Dermatol. 2020;83(2):343-363. doi:10.1016/j.jaad.2020.03.123

18. Decates TS, Velthuis PJ, Schelke LW, et al. Increased risk of lateonset, immune-mediated, adverse reactions related to dermal fillers in patients bearing HLA-B*08 and DRB1*03 haplotypes. Dermatol Ther. 2020:1-6. doi:10.1111/dth.14644

19. Friedman H, Newton C, Klein TW. Microbial infections, immunomodulation, and drugs of abuse. Clin Microbiol Rev. 2003;16(2):209-219.

20. Warren GW, Alberg A. Smoking cessation after a cancer diagnosis and survival in cancer patients. Am Soc Clin Oncol. 2018;36 (15):1561. doi:10.1200/JCO.2018.36.15_suppl.1561

21. Trivedi MK, Kroumpouzos G, Murase JE. A review of the safety of cosmetic procedures during pregnancy and lactation. Int $J$ Womens Dermatol. 2017;3(1):6-10. doi:10.1016/j.ijwd.2017.01.005
22. Humphrey S, Jones DH, Carruthers J, et al. Retrospective review of delayed adverse events secondary to treatment with a smooth, cohesive. J Am Acad Dermatol. 2020. doi:10.1016/j.jaad.2020.01.066

23. Shumaker PR, England LJ, Dover JS, et al. Effect of monopolar radiofrequency treatment over soft-tissue fillers in an animal model: part 2. Lasers Surg Med. 2006;38(3):211-217.

24. Hsu SH, Chung HJ, Weiss RA. Histologic effects of fractional laser and radiofrequency devices on hyaluronic acid filler. Dermatologic Surg. 2019;45(4):552-556. doi:10.1097/DSS.0000000000001716

25. Del Rosso JQ, Tanghetti E, Webster G, Gold LS, Thiboutot D, Gallo RL. Update on the management of rosacea from the American Acne \& Rosacea Society (AARS). J Clin Aesthet Dermatol. 2019;12(6):17.

26. Kuraitis D, Williams L. Decolonization of Staphylococcus aureus in Healthcare: a Dermatology Perspective. J Healthc Eng. 2018;2018:18. doi:10.1155/2018/2382050

27. Jiang Y-C, Feng H, Lin Y-C, Guo X-R. New strategies against drug resistance to herpes simplex virus. Int J Oral Sci. 2016;8(1):1-6. doi:10.1038/ijos.2016.3

28. Rowland-Warmann MJ. Hypersensitivity reaction to hyaluronic acid dermal filler following novel coronavirus infection-a case report. $J$ Cosmet Dermatol. 2021;20(5):1557-1562. doi:10.1111/jocd.14074

29. Munavalli GG, Knutsen-Larson S, Lupo MP, Geronemus RG. Oral angiotensin converting enzyme inhibitors for the treatment of delayed inflammatory reaction of dermal hyaluronic acid fillers following COVID-19 vaccination-a model for inhibition of angiotensin iiinduced cutaneous inflammation. JAAD Case Rep. 2021;10:63-68. doi:10.1016/j.jdcr.2021.02.018

30. Munavalli GG, Guthridge R, Knutsen-Larson S, Brodsky A, Matthew E, Landau M. COVID-19/SARS-CoV-2 virus spike protein-related delayed inflammatory reaction to hyaluronic acid dermal fillers: a challenging clinical conundrum in diagnosis and treatment. Arch Dermatol Res. 2021;1-15. doi:10.1007/s00403-020-02094-x

31. Alijotas-Reig J, Esteve-Valverde E, Gil-Aliberas N, Garcia-Gimenez V. Autoimmune/inflammatory syndrome induced by adjuvantsASIA - related to biomaterials: analysis of 45 cases and comprehensive review of the literature. Immunol Res. 2018;66(1):120-140. doi:10.1007/s12026-017-8980-5

32. Rice SM, Ferree SD, Mesinkovska NA, Kourosh AS. The art of prevention: COVID-19 vaccine preparedness for the dermatologist. Int $J$ Womens Dermatol. 2021;7(2):209-212. doi:10.1016/j. ijwd.2021.01.007

33. Naraghi M, Atari M. Development and validation of the expectations of aesthetic rhinoplasty scale. Arch Plast Surg. 2016;43(4):365. doi:10.5999/aps.2016.43.4.365

34. Krebs G, de la Cruz LF, Mataix-Cols D. Recent advances in understanding and managing body dysmorphic disorder. Evid Based Ment Health. 2017;20(3):71-75. doi:10.1136/eb-2017-102702

35. Focus D Deep focus' Cassandra report: Gen Z uncovers massive attitude shifts toward money, work and communication preferences. Market Wired; 2015.

36. Balakrishnan J, Griffiths MD. An exploratory study of "Selfitis" and the development of the Selfitis Behavior Scale. Int J Ment Health Addict. 2018;16(3):722-736. doi:10.1007/s11469-017-9844-x

37. Nightingale SJ, Wade KA, Watson DG. Can people identify original and manipulated photos of real-world scenes? Cogn Res Princ Implic. 2017;2(1):30. doi:10.1186/s41235-017-0067-2

38. Rice SM, Graber E, Kourosh AS. A pandemic of dysmorphia:"Zooming" into the perception of our appearance. Facial Plast Surg Aesthetic Med. 2020;22(6):401-402. doi:10.1089/ fpsam.2020.0454

39. Heydenrych I, Siolo E, Dlova NC, Avelar LE. Skin and structural aging in patients of African ethnicity. Features, management and the role of regenerative surgery. In: Kalaaji A, editor. Plastic and Aesthetic Regenerative Surgery and Fat Grafting: Clinical Application and Operative Techniques. Springer; 2021. 
40. Samizadeh S, Wu W. Ideals of facial beauty amongst the Chinese population: results from a large national survey. Aesthetic Plast Surg. 2018;42(6):1540-1550. doi:10.1007/s00266018-1188-9

41. Kapoor KM, Chatrath V, Anand C, et al. Consensus recommendations for treatment strategies in Indians using botulinum toxin and hyaluronic acid fillers. Plast Reconstr Surg Glob Open. 2017;5(12): e1574. doi:10.1097/GOX.0000000000001574

42. Glass DA. Current Understanding of the Genetic Causes of Keloid Formation. J Investig Dermatol Symp Proc. 2017;18(2):S50-S53. doi:10.1016/j.jisp.2016.10.024

43. Ginsberg BA. Dermatologic care of the transgender patient. Int $J$ Womens Dermatol. 2017;3(1):65-67. doi:10.1016/j. ijwd.2016.11.007

44. De Maio M, Heydenrych I. Myomodulation. In: Pirayesh A, Bertossi D, Heydenrych I, editors. Aesthetic Facial Anatomy Essentials for Injections. CRC Press; 2020.

45. Belhaouari L, Lopez-Tomasety M, Quinodoz P, De Boulle K. Myomodulation and hyaluronic acid. Prime J. 2020:57-61.

46. Joganathan V, Shah-Desai S. Awareness of management of hyaluronic acid induced visual loss: a British National Survey. Eye. 2020;1013. doi:10.1038/s41433-020-0810-7

47. Goodman GJ, Liew S, Callan P, Hart S. Facial aesthetic injections in clinical practice: pretreatment and posttreatment consensus recommendations to minimise adverse outcomes. Australas J Dermatol. 2020.

48. Robinson DM. In vitro analysis of the degradation of calcium hydroxylapatite dermal filler: a Proof-of-Concept Study. Dermatol Surg. 2018;44:5-9. doi:10.1097/DSS.0000000000001683

49. van Loghem J, Funt D, Pavicic T, et al. Managing intravascular complications following treatment with calcium hydroxylapatite: an expert consensus. J Cosmet Dermatol. 2020;19(11):2845-2858. doi:10.1111/jocd.13353

50. Yankova M, Pavicic T, Frank K, et al. Intraarterial degradation of calcium hydroxylapatite using sodium thiosulfate-an in vitro and Cadaveric Study. Aesthetic Surg J. 2021;41(5):NP226-NP236. doi:10.1093/asj/sjaa350

51. Casabona G, Marchese PB, Montes JR, Hornfeldt CS. Durability, behavior, and tolerability of 5 hyaluronidase products. Dermatologic Surg. 2018;44(11):42-50. doi:10.1097/DSS.0000000000001562

52. Pifferi C, Berthet N, Renaudet O. Cyclopeptide scaffolds in carbohydrate-based synthetic vaccines. Biomater Sci. 2017;5(5):953-965. doi:10.1039/C7BM00072C

53. Reinholz M, Clanner-Engelshofen BM, Heppt MV, et al. Dermal fillers do not induce upregulation of NLRP3 inflammasomes or expression of inflammatory cytokines in granulomas. $J$ Cosmet Dermatol. 2020;19(11):2838-2844. doi:10.1111/jocd.13341

54. Buhren BA, Schrumpf H, Bölke E, Kammers K, Gerber PA. Standardized in vitro analysis of the degradability of hyaluronic acid fillers by hyaluronidase. Eur J Med Res. 2018;23(1):1-6. doi:10.1186/s40001-018-0334-9

55. Beylot C, Auffret N, Poli F, et al. Propionibacterium acnes: an update on its role in the pathogenesis of acne. J Eur Acad Dermatol Venereol. 2014;28(3):271-278. doi:10.1111/jdv.12224

56. McLaughlin J, Watterson S, Layton AM, Bjourson AJ, Barnard E, McDowell A. Propionibacterium acnes and acne vulgaris: new insights from the integration of population genetic, multi-omic, biochemical and host-microbe studies. Microorganisms. 2019;7(5):128. doi:10.3390/microorganisms 7050128

57. De Boulle K. Management of complications after implantation of fillers. J Cosmet Dermatol. 2004;3(1):2-15. doi:10.1111/j.14732130.2004.00058.x

58. De Boulle K. Critical reflections on ArteFill, a permanent injectable product for soft tissue augmentation: mechanism of action and injection techniques, indications, and applications. Aesthetic Plast Surg. 2010;34(3):287-289. doi:10.1007/s00266-010-9521-y
59. Schelke LW, Decates TS, Velthuis PJ. Ultrasound to improve the safety of hyaluronic acid filler treatments. J Cosmet Dermatol. 2018;17(6):1019-1024. doi:10.1111/jocd.12726

60. Urdiales-Gálvez F, De cabo-Francés FM, Bové I. Ultrasound patterns of different dermal filler materials used in Aesthetics. $J$ Cosmet Dermatol. 2021;20(5):1541-1548. doi:10.1111/jocd.14032

61. Ward B, Ward M, Fried O, Paskhover B. Nasal distortion in shortdistance photographs: the selfie effect. JAMA Facial Plast Surg. 2018;20(4):333-335. doi:10.1001/jamafacial.2018.0009

62. Diefenbach S, Christoforakos L. The selfie paradox: nobody seems to like them yet everyone has reasons to take them. An exploration of psychological functions of selfies in self-presentation. Front Psychol. 2017;8:7. doi:10.3389/fpsyg.2017.00007

63. Clare S, Rowley S. Implementing the Aseptic Non Touch Technique $\left(\mathrm{ANTT}^{\mathbb{B}}\right)$ clinical practice framework for aseptic technique: a pragmatic evaluation using a mixed methods approach in two London hospitals. J Infect Prev. 2018;19(1):6-15. doi:10.1177/ 1757177417720996

64. Kirk-Bayley J, Challacombe S, Sunkaraneni S, Combes J The use of povidone iodine nasal spray and mouthwash during the current COVID-19 pandemic may protect healthcare workers and reduce cross infection. Available SSRN 3563092; 2020.

65. Peng X, Xu X, Li Y, Cheng L, Zhou X, Ren B. Transmission routes of 2019-nCoV and controls in dental practice. Int J Oral Sci. 2020;12 (1):1-6. doi:10.1038/s41368-020-0075-9

66. Pirayesh A, Bertossi D, Heydenrych I, editors. Aesthetic Facial Anatomy Essentials for Injections. Boca Raton: CRC Press; 2020.

67. Kapoor KM, Chatrath V, Li CQ, Bertossi D. Pinch anatomy: an injection guide for temple filler injections. Dermatol Ther. 2020;33 (6). doi:10.1111/dth. 13983

68. Chubb DP, Taylor GI, Ashton MW. True and "choke" anastomoses between perforator angiosomes: part ii. dynamic thermographic identification. Plast Reconstr Surg. 2013;132(6):1457-1464. doi:10.1097/ 01.prs. 0000434407.73390 .82

69. Ashton MW, Taylor GI, Corlett RJ. The role of anastomotic vessels in controlling tissue viability and defining tissue necrosis with special reference to complications following injection of hyaluronic acid fillers. Plast Reconstr Surg. 2018;141(6):818e-830e. doi:10.1097/ PRS.0000000000004287

70. Khan TT, Colon-Acevedo B, Mettu P, DeLorenzi C, Woodward JA. An anatomical analysis of the supratrochlear artery: considerations in facial filler injections and preventing vision loss. Aesthetic Surg J. 2017;37(2):203-208. doi:10.1093/asj/sjw132

71. Carley SK, Kraus CN, Cohen JL. Nitroglycerin, or not, when treating impending filler necrosis. Dermatologic Surg. 2020;46(1):31-40. doi:10.1097/DSS.0000000000002030

72. Sobierajewicz J, Naskręcki R, Jaśkowski W, Van der Lubbe RHJ. Do musicians learn a fine sequential hand motor skill differently than non-musicians? PLoS One. 2018;13(11):1-23. doi:10.1371/journal. pone. 0207449

73. Kapoor K, Kapoor P, Heydenrych I, Bertossi D. Vision loss associated with hyaluronic acid fillers: a systematic review of literature. Aesthetic Plast Surg. 2020;44(3):929-944. doi:10.1007/s00266-019-01562-8

74. Albornoz CA, Jhawar N, Durso TA, Hazan E, Wang JV, Saedi N. Preinjection aspiration for injectable fillers in aesthetic dermatology: trust or bust? J Cosmet Dermatol. 2020;19(5):1063-1064. doi:10.1111/jocd.13377

75. Wang JV, Hazan E, Hattier G, Torbeck RL, Khorasani H, Saedi N. Utility of preinjection aspiration for hyaluronic fillers: a novel in vivo human evaluation. $J$ Cutan Med Surg. 2020;24(4):12034 75420921387. doi:10.1177/1203475420921387

76. Kogan I, Korolik P, Cartier H, Adhoute H, Liberzon A. In vitro evaluation of aspiration of hyaluronic acid filler with a new saline flashing method. J Cosmet Dermatol. 2020;19(10):2513-2518. doi:10.1111/jocd.13651 
77. Goodman GJ, Magnusson MR, Callan P, et al. Neither positive nor negative aspiration before filler injection should be relied upon as a safety maneuver. Aesthetic Surg J. 2021;41(4):NP134-NP136. doi:10.1093/asj/sjaa215

78. Casabona G. Blood aspiration test for cosmetic fillers to prevent accidental intravascular injection in the face. Dermatologic Surg. 2015;41(7):841-847. doi:10.1097/DSS.0000000000000395

79. Carey W, Weinkle S. Retraction of the plunger on a syringe of hyaluronic acid before injection: are we safe? Dermatol Surg. 2015;41:S340-S346. doi:10.1097/DSS.0000000000000557

80. Goodman GJ, Magnusson MR, Callan P, et al. Aspiration before tissue filler-an exercise in futility and unsafe practice. Aesthetic Surg J. 2021. doi:10.1093/asj/sjab036

81. Goodman GJ, Liew S, Callan P, et al. Re Facial aesthetic injections in clinical practice: pretreatment and post-treatment consensus recommendations to minimise adverse outcome Region-specific changes in line with the Covid-19 pandemic. Australas J Dermatol. 2020. doi:10.1111/ajd.13374

82. Alvarez-Perea A, Tanno LK, Baeza ML. How to manage anaphylaxis in primary care. Clin Transl Allergy. 2017;7(1):1-10. doi:10.1186/ s13601-017-0182-7

83. Humzah MD, Ataullah S, Chiang CA, Malhotra R, Goldberg R. The treatment of hyaluronic acid aesthetic interventional induced visual loss (AIIVL): a consensus on practical guidance. J Cosmet Dermatol. 2019;18(1):71-76. doi:10.1111/jocd.12672

84. Goodman GJ, Magnusson MR, Callan P, et al. A consensus on minimizing the risk of hyaluronic acid embolic visual loss and suggestions for immediate bedside management. Aesthetic Surg J. 2019.

85. Paap MK, Milman T, Ugradar S, Goldberg R, Silkiss RZ. Examining the role of retrobulbar hyaluronidase in reversing filler-induced blindness: a systematic review. Ophthalmic Plast Reconstr Surg. 2019. doi:10.1097/PRS.0000000000005806

86. King M, Bassett S, Davies E, King S. Management of delayed onset nodules. J Clin Aesthet Dermatol. 2016;9(11):1-5.

87. Liew S. Ethnic and gender considerations in the use of facial injectables: Asian patients. Plast Reconstr Surg. 2015;136(5):22-27. doi:10.1097/PRS.0000000000001728
88. Cavallini M, Papagni M, Trocchi G. Sensitivity of hyaluronic acid fillers to hyaluronidase: an in vitro analysis. J Clin Exp Dermatol Res. 2020;11(517).

89. King M, Convery C, Davies E. The use of hyaluronidase in aesthetic practice the use of hyaluronidase in aesthetic practice. Aesthetic Complicat Expert Gr. 2019;2.4:1-12.

90. Rauso R, Zerbinati N, Fragola R, Nicoletti GF, Tartaro G. Transvascular hydrolysis of hyaluronic acid filler with hyaluronidase. Dermatologic Surg. 2020;47(3):370-372. doi:10.1097/dss.00000 00000002773

91. Rauso R, Zerbinati N, Franco R, et al. Cross-linked hyaluronic acid filler hydrolysis with hyaluronidase: different settings to reproduce different clinical scenarios. Dermatol Ther. 2020;33(2):1-5. doi:10.1111/dth.13269

92. De Boulle K, Glogau R, Kono T, et al. A review of the metabolism of 1, 4Butanediol Diglycidyl ether-crosslinked hyaluronic acid dermal fillers. Dermatologic Surg. 2013;39(12):1758-1766. doi:10.1111/dsu.12301

93. Kumar N, Swift A, Rahman E. Development of "Core Syllabus" for facial anatomy teaching to aesthetic physicians: a Delphi consensus. Plast Reconstr Surg Glob Open. 2018;6(3):1-7. doi:10.1097/ GOX.0000000000001687

94. Sindel A, Özalp O, Yıldırımyan N, Oğuz N, Sindel M, Llankovan V. Evaluation of the course of the marginal mandibular branch of the facial nerve: a fresh cadaveric study. Br J Oral Maxillofac Surg. 2021;59(2):179-183. doi:10.1016/j.bjoms.2020.08.020

95. Delorenzi C. New high dose pulsed hyaluronidase protocol for hyaluronic acid filler vascular adverse events. Aesthetic Surg J. 2017;37 (7):814-825. doi:10.1093/asj/sjw251

96. Mackern-Oberti JP, Jara EL, Riedel CA, Kalergis AM. Hormonal modulation of dendritic cells differentiation, maturation and function: implications for the initiation and progress of systemic autoimmunity. Arch Immunol Ther Exp (Warsz). 2017;65(2):123-136. doi:10.1007/ s00005-016-0418-6

\section{Publish your work in this journal}

Clinical, Cosmetic and Investigational Dermatology is an international, peer-reviewed, open access, online journal that focuses on the latest clinical and experimental research in all aspects of skin disease and cosmetic interventions. This journal is indexed on CAS.
The manuscript management system is completely online and includes a very quick and fair peer-review system, which is all easy to use. Visit http://www.dovepress.com/testimonials.php to read real quotes from published authors. 